\title{
Remote sensing of tropical ecosystems: Atmospheric correction and cloud masking matter
}

\author{
Thomas Hilker a,b,c,*, Alexei I. Lyapustin ${ }^{\text {a }}$, Compton J. Tucker ${ }^{a}$, Piers J. Sellers ${ }^{a}$, \\ Forrest G. Hall ${ }^{\mathrm{a}, \mathrm{b}}$, Yujie Wang a,b \\ a Oregon State University, College of Forestry, Corvallis, OR 97331, USA \\ b NASA Goddard Space Flight Center, 8800 Greenbelt Road, Greenbelt, MD 20771, USA \\ c Joint Center for Earth Systems Technology, University of Maryland Baltimore County, Baltimore, MD 21228, USA
}

\section{A R T I C L E I N F O}

\section{Article history:}

Received 27 April 2012

Received in revised form 15 July 2012

Accepted 5 August 2012

Available online 29 September 2012

\section{Keywords:}

Amazon

Atmospheric correction

Cloud screening

NDVI

Time series

Land surface product validation

MODIS

\begin{abstract}
A B S T R A C T
Tropical rainforests are significant contributors to the global cycles of energy, water and carbon. As a result, monitoring of the vegetation status over regions such as Amazônia has been a long standing interest of Earth scientists trying to determine the effect of climate change and anthropogenic disturbance on the tropical ecosystems and its feedback on the Earth's climate. Satellite-based remote sensing is the only practical approach for observing the vegetation dynamics of regions like the Amazon over useful spatial and temporal scales, but recent years have seen much controversy over satellite-derived vegetation states in Amazônia, with studies predicting opposite feedbacks depending on data processing technique and interpretation. Recent results suggest that some of this uncertainty could stem from a lack of quality in atmospheric correction and cloud screening. In this paper, we assess these uncertainties by comparing the current standard surface reflectance products (MYD09, MYD09GA) and derived composites (MYD09A1, MCD43A4 and MYD13A2 - Vegetation Index) from the Moderate Resolution Imaging Spectroradiometer (MODIS) onboard the Aqua satellite to results obtained from the Multi-Angle Implementation of Atmospheric Correction (MAIAC) algorithm. MAIAC uses a new cloud screening technique, and novel aerosol retrieval and atmospheric correction procedures which are based on time-series and spatial analyses. Our results show considerable improvements of MAIAC processed surface reflectance compared to MYD09/MYD13 with noise levels reduced by a factor of up to 10. Uncertainties in the current MODIS surface reflectance product were mainly due to residual cloud and aerosol contamination which affected the Normalized Difference Vegetation Index (NDVI): During the wet season, with cloud cover ranging between $90 \%$ and $99 \%$, conventionally processed NDVI was significantly depressed due to undetected clouds. A smaller reduction in NDVI due to increased aerosol levels was observed during the dry season, with an inverse dependence of NDVI on aerosol optical thickness (AOT). NDVI observations processed with MAIAC showed highly reproducible and stable inter-annual patterns with little or no dependence on cloud cover, and no significant dependence on AOT $(p<0.05)$. In addition to a better detection of cloudy pixels, MAIAC obtained about $20-80 \%$ more cloud free pixels, depending on season, a considerable amount for land analysis given the very high cloud cover (75-99\%) observed at any given time in the area. We conclude that a new generation of atmospheric correction algorithms, such as MAIAC, can help to dramatically improve vegetation estimates over tropical rain forest, ultimately leading to reduced uncertainties in satellite-derived vegetation products globally.
\end{abstract}

(C) 2012 Elsevier Inc. All rights reserved.

\section{Introduction}

The Amazon basin encompasses almost half the tropical rainforest of the planet, storing an estimated 100 billion tonnes of carbon (Atkinson et al., 2011) and accounting for about 15\% of global photosynthesis (Malhi et al., 2008), while hosting roughly a quarter of the world's terrestrial species (Dirzo \& Raven, 2003). Evapotranspiration

\footnotetext{
* Corresponding author at: Oregon State University, College of Forestry, Corvallis, OR 97331, USA. Tel.:+1 5417372608.

E-mail address: thomas.hilker@oregonstate.edu (T. Hilker).
}

over Amazônia is a major factor of global energy and water circulation and affects precipitation rates across the Americas and large parts of the northern hemisphere (Werth \& Avissar, 2002). Alterations of this ecosystem due to anthropogenic disturbance and climate change could have dramatic effects on the global carbon and energy balance (Gedney \& Valdes, 2000). For instance, increased sea surface temperatures in the Pacific ocean could intensify El Niño southern oscillation events and associated periodic Amazon droughts, while higher Atlantic sea surface temperatures and the northwest displacement of the intertropical convergence zone (Li et al., 2006) could cause these droughts to occur more frequently (Malhi et al., 2008). Some global circulation models (GCMs) predict that these drought effects alone may turn the 
currently estimated carbon sink of Amazônia into a source, thereby substantially affecting rates of global climate change (Lewis et al., 2011).

As a result, accurate monitoring of the Amazon is essential for estimating future climate scenarios, predicting global energy fluxes and precipitation rates, and assessing the success of conservation efforts, such as the United Nation's REDD (reducing emissions from deforestation and degradation) initiative (Mollicone et al., 2007). While satellite remote sensing provides the only viable means to observe the Amazon in a spatially comprehensive and temporally frequent fashion, spaceborne optical assessment of tropical vegetation is inherently difficult due to high cloud cover, high aerosol concentration from biomass burning and limited physical access to ground validation sites. Consequently, recent years have seen much controversy over satellite derived estimates of the vegetation status in Amazônia. For instance, Saleska et al. (2007) reported an increase in vegetation greenness over the Amazon during the 2005 drought based on MYD13A2 observations from MODIS. This study was subsequently challenged by others, most notably Samanta et al. (2010) and Atkinson et al. (2011) on the basis of poor data quality and processing methodology. In response to a second drought event in 2011, Xu et al. (2011) reported a widespread decline in Amazon greenness, thereby directly contradicting the results reported by Saleska et al. (2007) for the 2005 drought. Similarly, Zhao and Running (2010) reported a 1\% decrease in global primary productivity between 2001 and 2009, which was based largely on a decrease in primary productivity (and $\left.f_{P A R}\right)$ in the Amazon, a result subsequently challenged by Samanta et al. (2011) and Medlyn (2011).

Recent work (Forster \& Ramaswamy, 2007; Levy et al., 2010) suggests a substantial uncertainty of atmospheric aerosol properties from MODIS data over the Amazon region as potential cause of these discrepancies (Zelazowski et al., 2011). These uncertainties could introduce errors in discrete and continuous land surface parameters, such as land cover classes (Lu \& Weng, 2007) and vegetation indices (Myneni \& Asrar, 1994) throughout the Amazon basin (Zelazowski et al., 2011). The current MODIS land surface reflectance product (MOD09/MYD09) routinely corrects for atmospheric scattering using models of the radiative transfer of light through the atmosphere (Vermote \& Kotchenova, 2008). While this technique is widely applied, it uses a single observation to characterize a pixel value driven by two main unknowns, aerosol optical thickness (AOT) and surface reflectance (SR) and, as a result, a priori assumptions are required to describe their relationship. For instance, the current aerosol retrieval algorithm of MOD04/MYD04 (Kaufman et al., 1997; Levy et al., 2007) relates surface reflectance in the visible (blue and red) spectral bands with MODIS band $7(2.1 \mu \mathrm{m})$ reflectance by using a prescribed spectral regression coefficient (SRC). A Lambertian surface model is then applied for aerosol retrievals and atmospheric correction. While this technique greatly simplifies data processing, the Lambertian assumption reduces the anisotropy of the derived reflectance and introduces an error that depends on the aerosol amount and the view-observer geometry (Lyapustin, 1999; Wang et al., 2010).

In addition to the uncertainties from the Lambertian assumption, pixel-based algorithms have to rely on spectral reflectance and thermal thresholds for cloud masking. However, lack of a priori knowledge about the specific cloud free reflectance makes the distinction between cloudy and clear observations difficult (Yang \& Di Girolamo, 2008). Traditionally, a generic land type classification has been used to address this limitation by substituting a standard reflectance value for clear pixels; however, considerable uncertainties remain due to the wide natural variability of both land surface and cloud reflectance (Lyapustin et al., 2008; Rossow \& Garder, 1993).

MAIAC grids MODIS L1B data to a $1 \mathrm{~km}$ resolution, and accumulates measurements of the same surface area from different orbits (view geometries) for up to 16 days of observations for equatorial and up to 4 days for polar regions using a moving window approach. The MAIAC cloud mask (CM) algorithm composes a dynamically updated reference clear-sky image of the surface from spatial and time series analyses. The knowledge of reference clear-sky reflectance in addition to spectral and thermal reflectance tests (Ackerman et al., 1998) has been shown to improve cloud detection (for detail, see Lyapustin et al., 2008). MAIAC aerosol retrieval (Lyapustin et al., 2011b) and atmospheric correction (Lyapustin et al., this issue) algorithms use an advanced radiative transfer theory with anisotropic land surface reflectance (Lyapustin \& Knyazikhin, 2001) parameterized by the Ross-Thick Li-Sparse (RTLS, Roujean et al., 1992) bidirectional reflectance model (Lyapustin et al., 2011a). Once RTLS in MODIS band $7(2.13 \mu \mathrm{m})$ is initialized, the aerosol algorithm derives a spectral regression coefficient (SRC) for each $1 \mathrm{~km}$ grid cell by simultaneously processing $25 \times 25 \mathrm{~km}^{2}$ blocks of pixels from four or more cloud-free observations obtained from different view angles. Knowledge of SRC allows aerosol retrievals at $1 \mathrm{~km}$ resolution over spatially heterogeneous surfaces, and helps to avoid dependence of derived AOT on surface brightness (Lyapustin et al., 2011b). Finally, the atmospheric correction algorithm (see Lyapustin et al., this issue) derives parameters of the RTLS model for each $1 \mathrm{~km}$ grid cell along with spectral surface albedo and a bidirectional reflectance factor (BRF). An overview of all components of MAIAC is provided in Lyapustin and Wang (2009).

Algorithms like MAIAC, with more complete descriptions of the physical system and limited role of empirical assumptions, hold promise to overcome many of the restrictions currently faced by conventional satellite retrievals over tropical regions. In this paper, we compare MODIS standard atmospheric correction from Aqua (using the MYD09 and MYD13 reflectance products) to MAIAC results over the Amazon basin and assess the potentials and limitations of satellite retrievals of vegetation greenness over Amazônia. The implications for determining the biophysical state of the rainforest and detecting changes over time are being discussed for the different products.

\section{Methods}

\subsection{Data}

The study encompasses two MODIS tiles (h11v09 and h11v08), an area of 2.88 million $\mathrm{km}^{2}$, spanning $10^{\circ} \mathrm{N}$ to $10^{\circ} \mathrm{S}$ in latitude and $70^{\circ} 30^{\prime}$ $\mathrm{W}$ to $62^{\circ} \mathrm{W}$ in longitude (Fig. 1). The area is characterized by seasonal tropical savannah and seasonal rain forest in the north, while the southern part consists of evergreen tropical forest. We used MODIS data from the Aqua satellite platform collected between 2002/07/04 and 2010/12/31. Collection 5 data of the MYD09GA $1 \mathrm{~km}$ daily surface reflectance product and the MYD09A1 eight-day composite product were obtained from EOS data gateway of NASA's Goddard Space Flight Center (https://wist-ops.echo.nasa.gov/api/) and data mosaicking was performed using the MODIS reprojection tool (MRT). Clouds were masked by means of the 'state_ $1 \mathrm{~km}$ ' scientific dataset (SDS) included in the MYD09GA product ('state_500m' in case of MYD09A1), which is based on two cloud detection algorithms, the MOD/MYD35 cloud mask (Frey et al., 2008) and an additional, internal cloud screening (Vermote et al., 2008). In addition to cloud masking, all MYD09 data were quality filtered using the MYD09 quality $\left(Q_{A}\right)$ flags and only cloud free pixels with high data quality were passed and used for all subsequent analyses (Vermote et al., 2008). An overview of the quality and cloud flags set for quality assurance is given in Table 1 .

In addition to MYD09, we also acquired the MODIS 16-day $500 \mathrm{~m}$ vegetation index (VI) product, MYD13A2, for the same observation period from the same data gateway. Data quality was assured using the "500 m 16 days VI Quality' flags as well as the ‘ $500 \mathrm{~m} 16$ days pixel reliability، layer to allow only pixels with good quality and high reliability rating to pass (see Table 1). The MYD13A2 product supplies both NDVI and the Enhanced Vegetation Index (EVI), however in this study we focussed on the effect of atmospheric correction and cloud screening on NDVI. The compositing algorithms, MYD09A1 and MYD13A2, accumulate observations over 8 and 16 days, respectively, and use pixel 


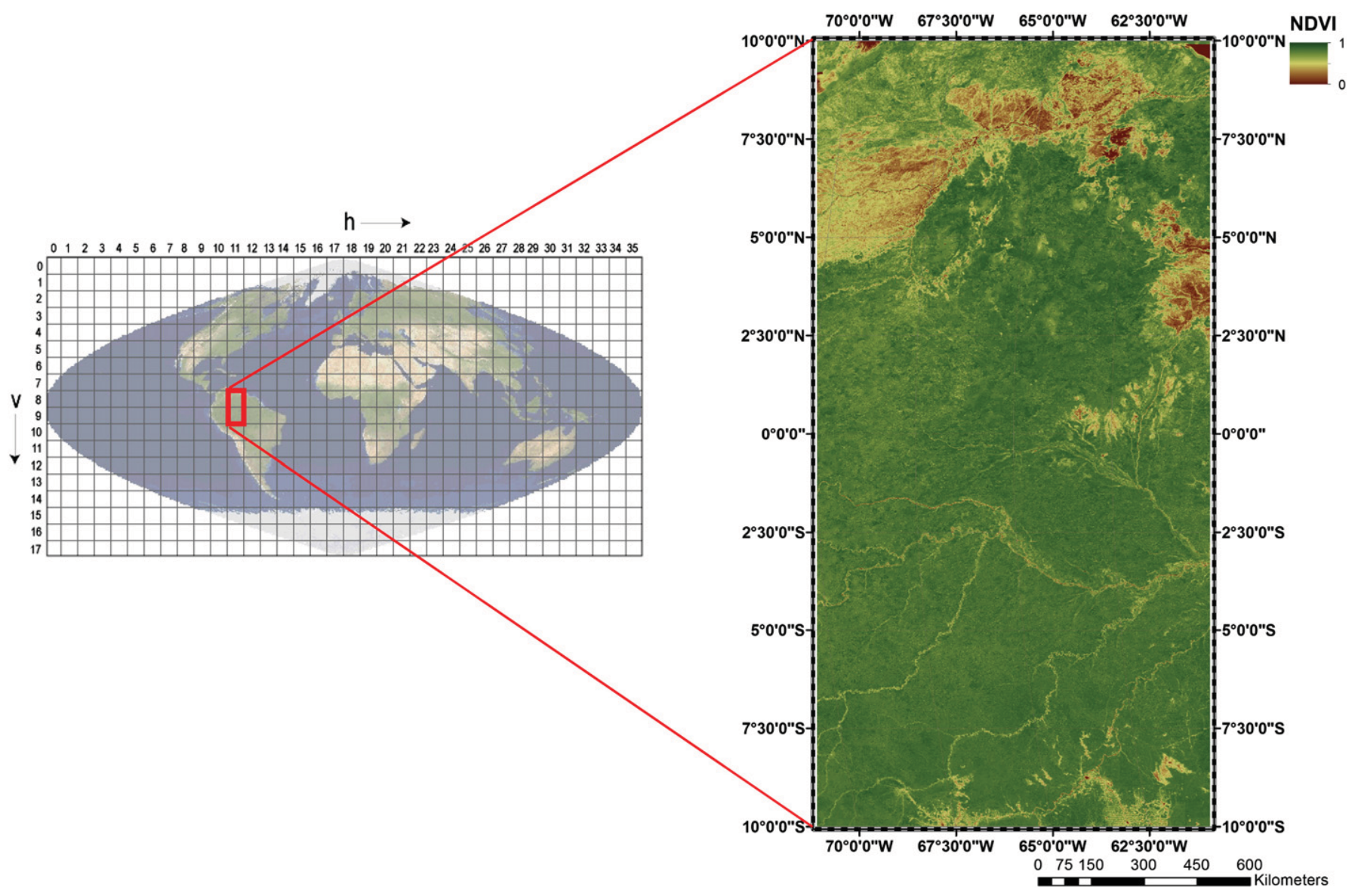

Fig. 1. Study site. The study area encompasses two MODIS tiles, spanning an area of 2.88 million $\mathrm{km}^{2}$.

values with darkest surface reflectance (highest NDVI in case of MYD13A2) and closest to nadir view angle to represent a given location and compositing cycle.
MODIS Aqua calibrated and geometrically corrected (Level 1B) data acquired between $2002 / 07 / 04$ and $2010 / 12 / 31$ for the same area were also processed by MAIAC. For this study, we used the

Table 1

Quality /cloud flags of the MYD09GA, MYD09A1, MYD13A2 and MCD43A2 (for MCD43A4 quality) products used in this study. Flags that are not mentioned were not used.

\begin{tabular}{|c|c|c|c|c|}
\hline Product & SDS name & Flag & Accepted values & \\
\hline \multirow[t]{11}{*}{ MYD09GA } & \multirow[t]{4}{*}{ QC $500 \mathrm{~m}$} & MODLAND QA bits & 00 & (ideal quality - all bands) \\
\hline & & band 1 data quality & 0000 & (highest quality) \\
\hline & & band 2 data quality & 0000 & (highest quality) \\
\hline & & atm. corr. performed & 1 & (yes) \\
\hline & \multirow[t]{7}{*}{ State $1 \mathrm{~km}$} & cloud state & 00 & (clear) \\
\hline & & cloud shadow & 0 & (no) \\
\hline & & aerosol quantity & $00 / 01$ & (climatology/low) \\
\hline & & cirrus detected & 00 & (none) \\
\hline & & internal cloud flag & 0 & (no cloud) \\
\hline & & fire flag & 0 & (no fire) \\
\hline & & pixel adjacent to cloud & 0 & (no) \\
\hline \multirow[t]{2}{*}{ MYD09A1 } & QC $500 \mathrm{~m}$ & see 'QC 500 m' for MYD09GA & & \\
\hline & State $500 \mathrm{~m}$ & see 'State 1' km for MYD09GA & & \\
\hline \multirow[t]{8}{*}{ MYD13A2 } & VI Quality & MODLAND QA Bits & 00 & (VI produced with good quality) \\
\hline & & VI Usefulness & 0000 & (Highest quality) \\
\hline & & & 0001/0010/0100/1000 & (Lower quality) \\
\hline & & aerosol quantity & $00 / 01$ & (climatology/low) \\
\hline & & adjacent cloud & 0 & (no) \\
\hline & & mixed cloud & 0 & (no) \\
\hline & & possible shadow & 0 & (no) \\
\hline & Pixel reliability & Rank Key & 0 & (Good data - use with confidence) \\
\hline \multirow[t]{6}{*}{ MCD43A2 (appendix) } & Albedo Quality & & 0 & (Processed, good quality) \\
\hline & & & 1 & (Processed, see other QA) \\
\hline & Albedo Band Quality & Band 1 & 0000 & (best quality) \\
\hline & & & 0001 & (good quality) \\
\hline & & Band 2 & 0000 & (best quality) \\
\hline & & & 0001 & (good quality) \\
\hline
\end{tabular}


following MAIAC outputs: cloud mask, aerosol optical thickness (AOT), bidirectional reflectance factors (BRF, also known as surface reflectance), and RTLS model parameters for the red and near-IR MODIS bands. MAIAC data does not include quality flags, but rather provides observations only for those pixels that were found not to be cloud contaminated and for which a stable aerosol correction could be made.

We used the BRF (or surface reflectance) values from both the MYD standard products and MAIAC to compare the effects of cloud masking and aerosol correction on the assessment of vegetation status from MODIS. A separate assessment of the BRDF-normalization (to remove view geometry variations) on MODIS NDVI can be found in the appendix.

\subsection{Approach}

We conducted a comparative analysis of cloud mask, aerosol, and NDVI between MAIAC and the respective operational MODIS algorithms. Performance of the two cloud screening algorithms (MYD35/MYD09 and MAIAC) was assessed relative to each other, by computing errors of omission/commission of MYD35/MYD09 using MAIAC as a reference. Further, MAIAC aerosol retrievals were qualitatively compared to the MODIS operational aerosol product MYD04 as the internal aerosol product of MOD09, which is based on similar principles as the Dark Target method of MYD04 (Vermote \& Kotchenova, 2008) but at a $1 \mathrm{~km}$ resolution, is not reported. The MYD04 Level 2 data is available at a $10 \mathrm{~km}$ spatial resolution and was gridded to the same sinusoidal projection as MAIAC, MYD09 and MYD13 to allow a direct comparison between the data products.

The normalized difference vegetation index was computed using MODIS bands 1 and 2 from the two MYD09 products (MYD09GA and MYD09A1) and from MAIAC, and was also acquired directly from MYD13A2. The MAIAC NDVI was computed from MAIAC BRF data in order to be directly comparable to MYD09GA, MYD09A1 and MYD13A2 NDVI. The area studied in this work includes seasonal tropical forests and savannahs in the north (Fig. 1), which are expected to show seasonal variability in vegetation greenness driven by the regular changes between dry and wet season. Relatively little variability is, however, expected in the southern part of the study area, which is covered by dense evergreen forest. As a result of the climatological conditions found in the study area, it can be assumed that vegetation indices related to greenness should be relatively stable over short periods of time (a few days) as there is no physiological reason for rapid and notable changes vegetation greenness (>5-10\%). The short-term stability of NDVI can therefore be seen as an indicator of data quality, since high frequency changes in NDVI will most likely be driven by cloud and aerosol artifacts rather than changes in vegetation status.

\section{Results}

Fig. 2 shows a comparison of NDVI time series obtained from MYD09GA, MYD09A1, MYD13A2 and MAIAC across six $50 \times 50 \mathrm{~km}^{2}$ spatial subsets of the study area. The subsets were selected using regularly spaced raster sampling to obtain representative regions for both seasonal and non-seasonal vegetation (as marked in the map). To allow a comparison between the daily, biweekly and monthly products, we first computed monthly mean values for each pixel by averaging all valid (that is cloud screened, and quality filtered) pixels acquired during a month. The arithmetic means and standard deviations shown in Fig. 2 were then obtained by averaging the monthly values across each $50 \times 50 \mathrm{~km}^{2}$ block. It is important to note that our processing approach excludes temporal variability in the standard deviation shown since each pixel is represented by only one monthly value, regardless of whether MYD09GA, MYD09A1, MYD13A2 or MAIAC was used. As a result, the standard deviations describe only variability due to heterogeneity of the landscape. Differences between these standard deviations can be attributed to differences in cloud screening and atmospheric correction since all datasets describe the identical area over the same time period. The largest variability in NDVI was found for the MYD09GA $1 \mathrm{~km}$ daily surface reflectance product across all samples, while the errorbars were smaller for the MYD09A1 composite (Fig. 2). The 16-day composite showed the least variability of all conventionally processed products, but scattering was still about twice as large as that from MAIAC dataset, which showed an up to 10 -fold reduction in spatial variability compared to the daily MYD product. The northern sites exposed a clear seasonal signal of NDVI across all examined MODIS datasets, while little seasonal variability was found for the two equatorial and the southern regions.

\subsection{Cloud masking}

Overall, a good correlation was found between MYD35 and MAIAC in cloud detection $\left(r^{2}=0.75\right)$, however, MAIAC cloud screening yielded significantly more cloud free observations than MYD35/ MYD09 (Figs. 3, 4). Fig. 3A presents a false color NIR image of the entire study area observed on July 16, 2002 (day of year, DOY=197); the high cloud fraction typical for the Amazon basin is visible in both cloud screening products (Fig. 3B and C). For this overpass, the MYD09/MYD35 cloud mask (Fig. 3B) identified 6.84\% of the image as cloud free, significantly less than the MAIAC algorithm (Fig. 3C), which found cloud free pixels in $14.34 \%$ of the entire image area. Depending on algorithm and season, the detected cloud cover was between $75 \%$ and $99 \%$ of the total area across all examined MODIS scenes (Fig. 4). Seasonal variation in cloud cover was in the order of $10-15 \%$ between the wet and dry seasons. On average, the area marked as cloudy by MAIAC was about $4 \%$ less than that masked by MYD09/MYD35 which, given the cloud cover, provides on average between $20-80 \%$ more cloud-free data for the land analysis in Amazon basin, depending on season.

Fig. 5 shows a comparative metric of cloudy/clear pixel classification of MYD09/MYD35 relative to that of MAIAC. The red line shows the relative accuracy of the MYD09/MYD35 cloud detection (the ratio of the number of detected cloud pixels to that of MAIAC is called user accuracy). The difference between $100 \%$ and this line represents the error of commission (relative to MAIAC), when MYD09/MYD35 classified a pixel as being cloudy, whereas the reference algorithm (MAIAC) did not. As the majority of pixels in each scene is classified as cloudy in both algorithms, the relative error of commission is low ( $6 \%$ ). The difference between $100 \%$ and the black line represents the error of omission when MYD09/MYD35 failed to detect a cloud, relative to MAIAC cloud mask.

The relative accuracies for cloud-free pixels derived from MYD09/ MYD35 and MAIAC were significantly lower, as only $1 \%$ to $25 \%$ of each image area was cloud-free, and as a result, a misclassification error of the same number of pixels is relatively larger. The green and blue lines show the omission/commission error for the clear pixels. The green line gives the percentage of pixels classified as clear by MYD09/MYD35 while MAIAC classified them as cloudy, whereas the blue line shows cases where MYD09/MYD35 classified a pixel as cloudy while MAIAC did not.

\subsection{Aerosol optical depth}

To illustrate differences in aerosol optical thickness between the MAIAC and operational MODIS aerosol retrievals (MYD04), we contrasted the distribution of AOT for a seasonal (northern) and a non-seasonal (southern) region of the study area using the year 2005 as an example; a year that saw a significant drought with associated intense biomass burning (Fig. 6). The selected areas correspond to the top left (Fig. 6A and C) and bottom left regions (Fig. 6B and D) shown in Fig. 2. To account for difference in resolution ( $1 \mathrm{~km}$ in MAIAC vs $10 \mathrm{~km}$ in MYD04), data were averaged over a 


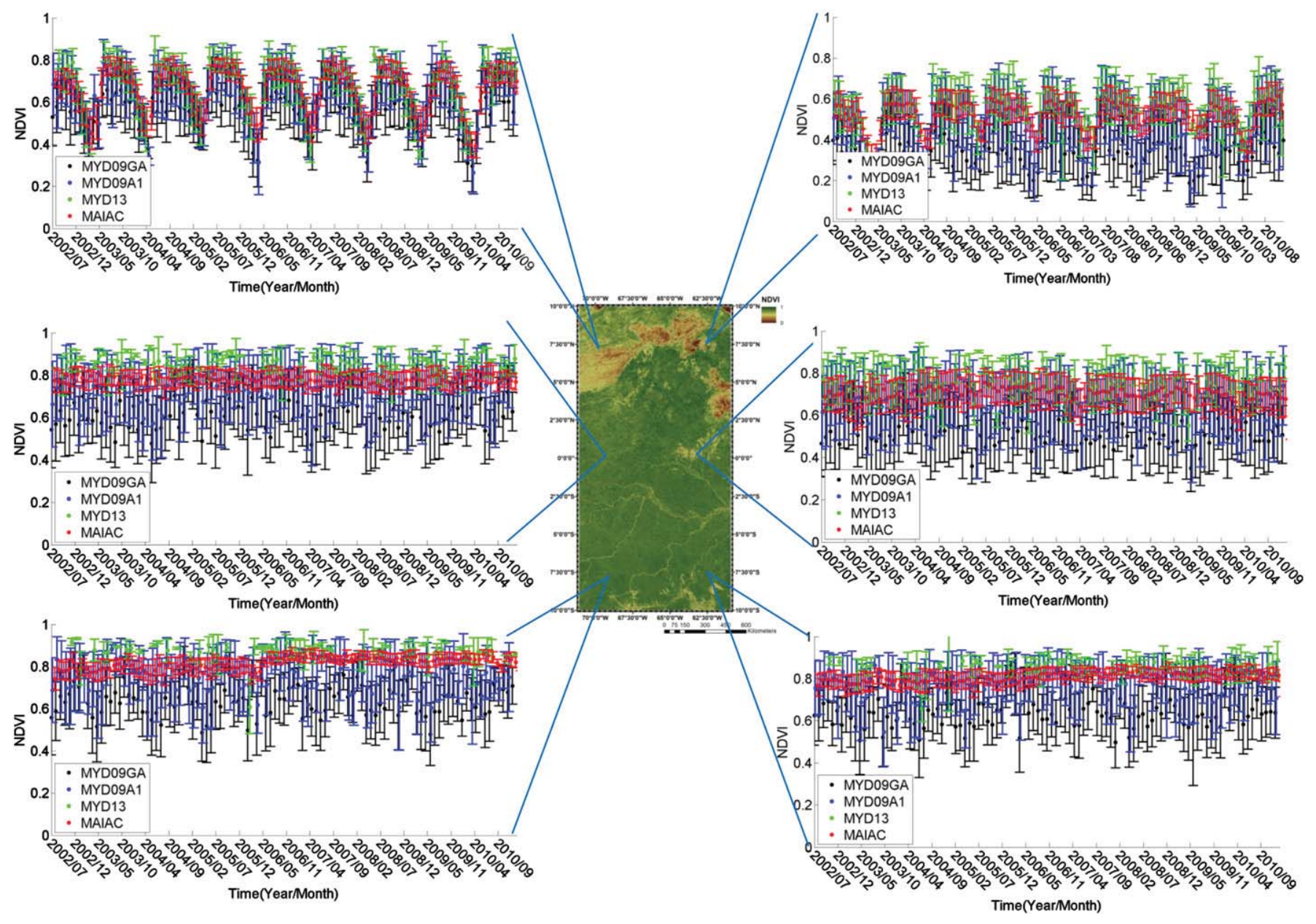

Fig. 2. Monthly observations of NDVI from MYD09GA (1 km daily surface reflectance), MYD09A1 (8-day composites), MYD13A2 (16-day vegetation index product) and MAIAC obtained over a $50 \times 50 \mathrm{~km}$ area as indicated in the map. The errorbars represent the mean spatial variability over the $50 \times 50 \mathrm{fm}$ subset $($ Please note that the points and errorbars of the products are slightly offset from each other for purposes of readability).

larger area of $500 \times 500 \mathrm{~km}^{2}$. The top row in Fig. 6 illustrates MAIAC aerosol optical thickness at $0.47 \mu \mathrm{m}$, the bottom row shows the corresponding MYD04 AOT at $0.55 \mu \mathrm{m}$. In the northern region (left column), AOT was relatively stable throughout the year with most observations around 0.2-0.3 and much less frequent higher AOT values. In the southern region (right column), AOT showed a clear seasonality with low values during the wet season and high average AOT related to biomass burning during the dry season. A somewhat lower MYD04 AOT is mostly explained by the wavelength difference of the AOT product (Levy et al., 2007; Lyapustin \& Wang, 2009). While MAIAC and MYD04 exposed similar patterns for both regions, the MAIAC AOT product shows a smoother frequency distribution over time (y-axis), in part due to higher spatial resolution. Fig. 7 shows a direct comparison between AOT derived from MAIAC and MYD04 across the entire study area (the two tiles), resampled to $100 \mathrm{~km}^{2}$ to account for the difference in spatial resolution existing between the two products. AOT derived from MAIAC shows a good correspondence to that derived from MYD04 throughout the study period (data shown between 2002 and 2010). The relationship was not significantly biased with an $r^{2}$ of 0.84 at $p<0.01$.

\subsection{NDVI}

To analyze the implications of the observed differences in cloud masking and AOT on vegetation studies, we assessed the spatial and temporal variability in NDVI using the same northern and southern sample areas shown in Fig. 2. Figs. 8 and 9 present NDVI estimates (along z-axis) as a function of time during 2002-2010 (x-axis). The $y$-axis shows the spatial variability of NDVI when averaged over different areas, from $2 \times 2$ to $50 \times 50 \mathrm{~km}^{2}$. The color represents the standard deviation $(\sigma)$ of the spatially averaged NDVI estimates. Since the tropical landscape is fairly homogeneous (particularly in the south), $\sigma$ mostly characterizes processing errors from clouds and aerosols, at least over smaller areas (up to $100 \mathrm{~km}^{2}$ ). The color bar shows that at these scales the MAIAC NDVI uncertainty is small, about $0.01-0.02$, which represents the total retrieval error (Figs. $8 \mathrm{~A}$ and $9 \mathrm{~A}$ ). The uncertainty increases to about $0.04-0.05$ at larger scales $\left(\approx 30-50 \mathrm{~km}^{2}\right)$ reflecting the landscape spatial variability. The vegetation signal in the north was strongly driven by seasonal effects (Fig. 8A), while in the south, almost no temporal or spatial changes were observed (Fig. 9A). Despite the differences in AOT, cloud cover and vegetation dynamics found between the northern and southern study area, MAIAC produced a highly consistent and reproducible NDVI time record.

Compared to MAIAC, $\sigma$ of MYD09GA-based NDVI estimates was about 10-fold higher and ranged between 0.15 and $0.20(>0.25$ in several areas) even when aggregating relatively few pixels $\left(\approx 100 \mathrm{~km}^{2}\right)$ (Figs. 8B and 9B). Results for the southern site show that the uncertainty in NDVI remained high at all spatial scales, indicating that the algorithm errors are significantly higher than spatial variability of the vegetation. This increased uncertainty in the MYD09 estimates compared to MAIAC can be attributed to both 
A

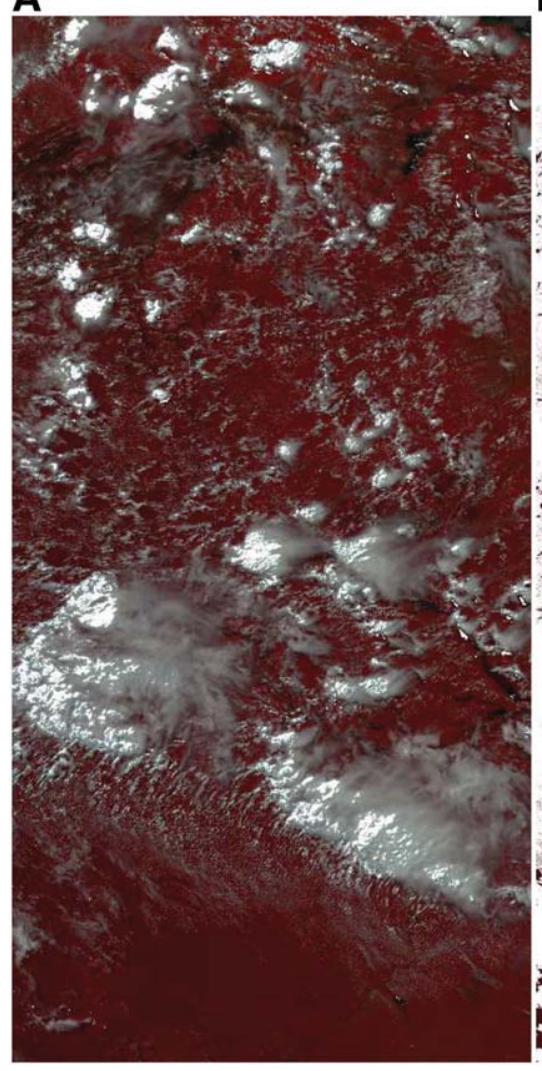

B

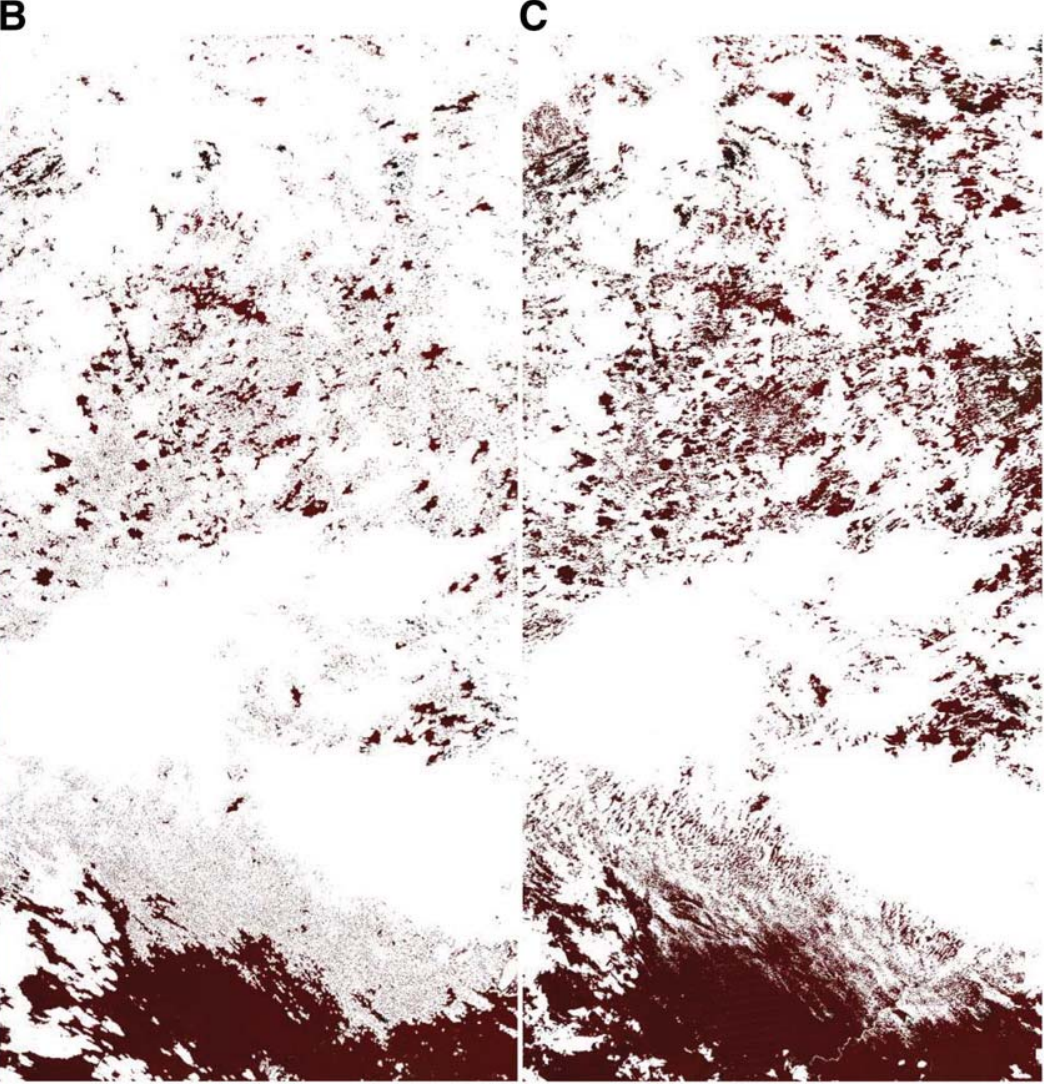

Fig. 3. Comparison of MYD09/MYD35 and MAIAC cloud mask. (A) False color infrared image acquired over the study area on July 16, 2002. (B) MYD09/MYD35 derived cloud mask overlaid on top of the same image (C) MAIAC derived cloud mask.

cloud masking and aerosol correction errors. The low AOT found at the northern site and also at the southern site during the wet season, at least in 2005, suggests that this variability is mainly due to the cloud masking errors. To assess the contributions of AOT and cloud masking in more detail, we repeated the same analysis as shown in Figs. 8B and 9B but using MYD09GA product filtered by the MAIAC cloud mask. The results of these analyses are shown in Figs. 8C and $9 \mathrm{C}$, for the northern and southern study area, respectively. The resulting NDVI values were notably smoother and had a much more consistent time record approaching the MAIAC results (shown in
Figs. 8A and 9A). This confirms that most of the MYD09GA errors were due to cloud masking. Compared to Figs. 8B and 9B, $\sigma$ was reduced to 0.02 and 0.1 , respectively, suggesting that cloud contamination was responsible for about $80 \%$ of uncertainties seen in these Figures. Nonetheless, even with the MAIAC cloud filter applied, the MYD09GA NDVI uncertainty was about twice that of MAIAC.

The MYD09A1 and MYD13A2 compositing (Figs. 8D and 9D, and Figs. $8 \mathrm{E}$ and $9 \mathrm{E}$, respectively) had only limited effects on improving the uncertainties of the conventional NDVI product. For the northern study area, $\sigma$ ranged between 0.03 to 0.1 for the MYD09A1 product,

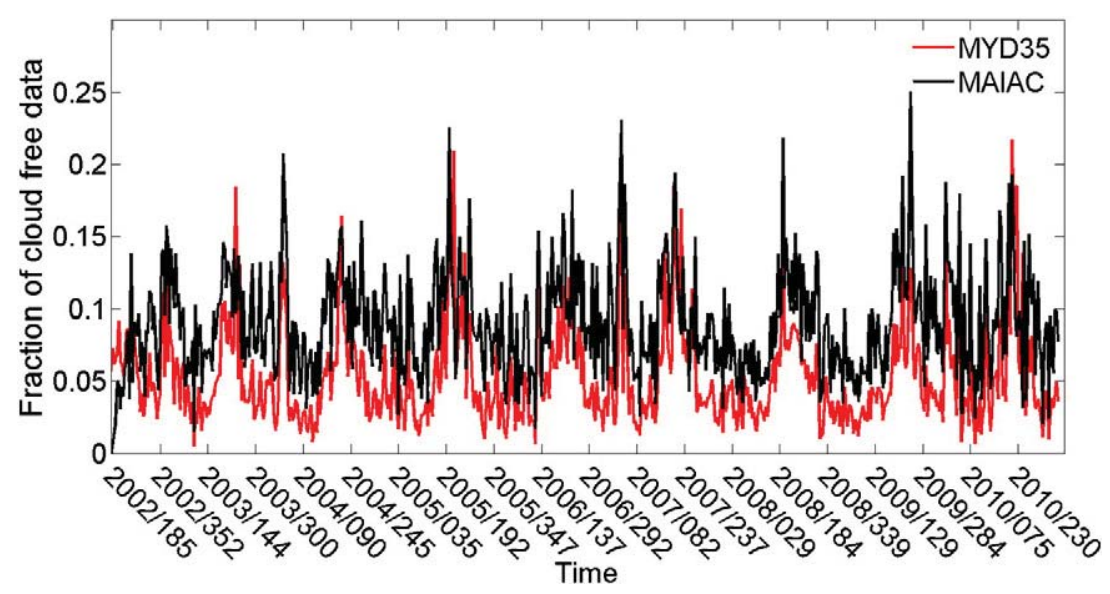

Fig. 4. Comparison between the fraction of cloud free pixels acquired throughout the study period from MAIAC (black) and MYD09/MYD35 (red). MYD09/MYD35 was consistently more conservative than MAIAC, cloud cover was heavily dependent on season. 


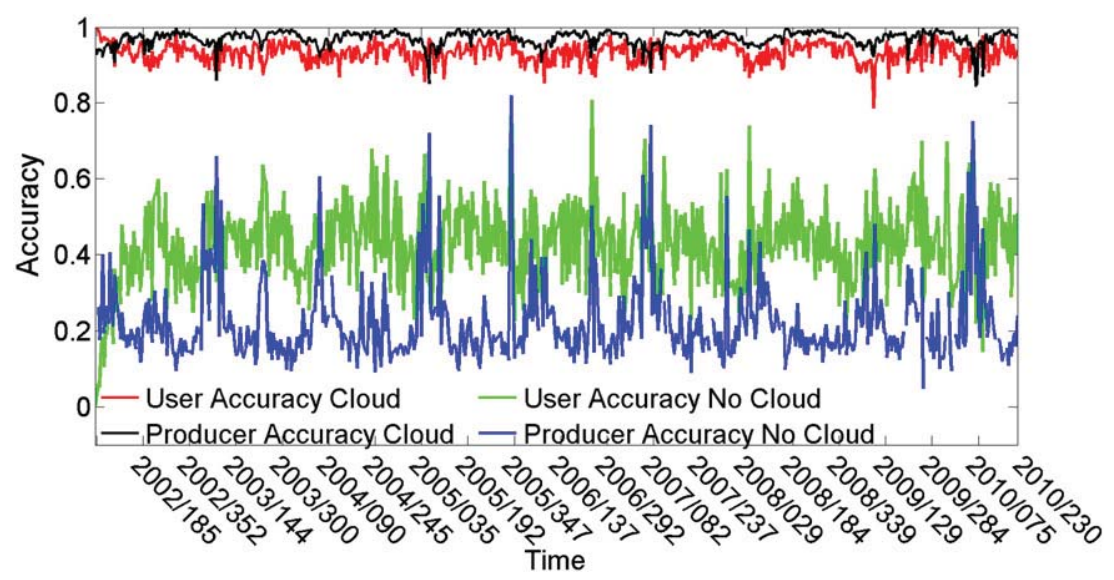

Fig. 5. Errors of omission and commission for cloud and non cloud pixels acquired from confusion matrices of each acquisition date comparing MYD09/MYD35 cloud mask to MAIAC. One minus the red line represents the fraction of cases where MYD09/MYD35 classified pixel as cloudy, whereas MAIAC found this pixel to be cloud free. One minus the black line represents the fraction of cases, in which MAIAC identified a pixel as being cloudy, while MYD09/MYD35 marked it as cloud free. The green line shows the percentage of cloud free pixels found by MYD09/MYD35 but marked as cloudy in MAIAC, whereas the blue line shows cases in which MAIAC had identified a pixel as cloud free but not MYD09/MYD35.

while for the 16-day MYD13A2 product, $\sigma$ was reduced to 0.025 and 0.09 compared to MYD09GA. Similarly, for the southern area, $\sigma$ ranged between 0.02 and 0.1 for MYD09A1, and between 0.01 and 0.05 for MYD13A2 products. Residual cloud contamination was apparent in the composite products, especially in the south, showing inconsistent annual patterns and frequent spatial outliers (compare also Fig. 2).

The results presented in Figs. 8 and 9 are consistent with the findings presented in Fig. 10, which shows a direct comparison of NDVI obtained from MAIAC and MYD09GA across the entire study area.
A

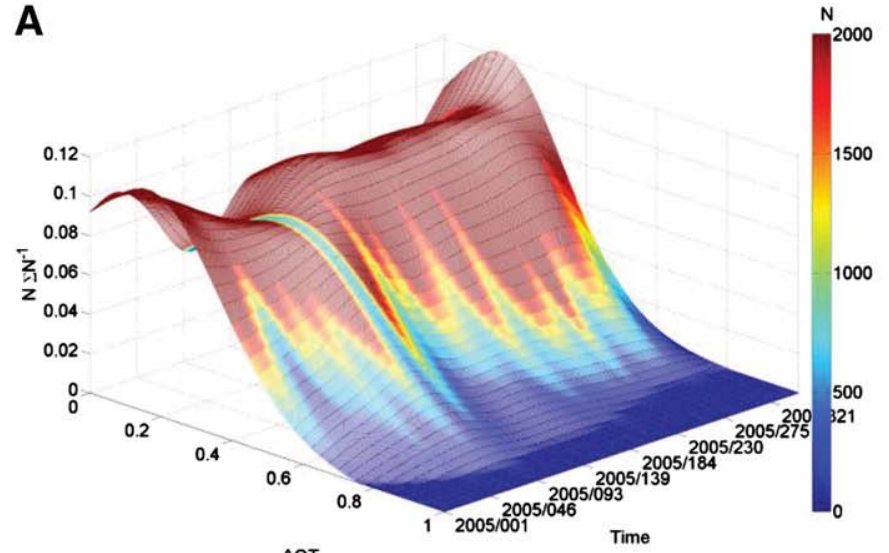

C

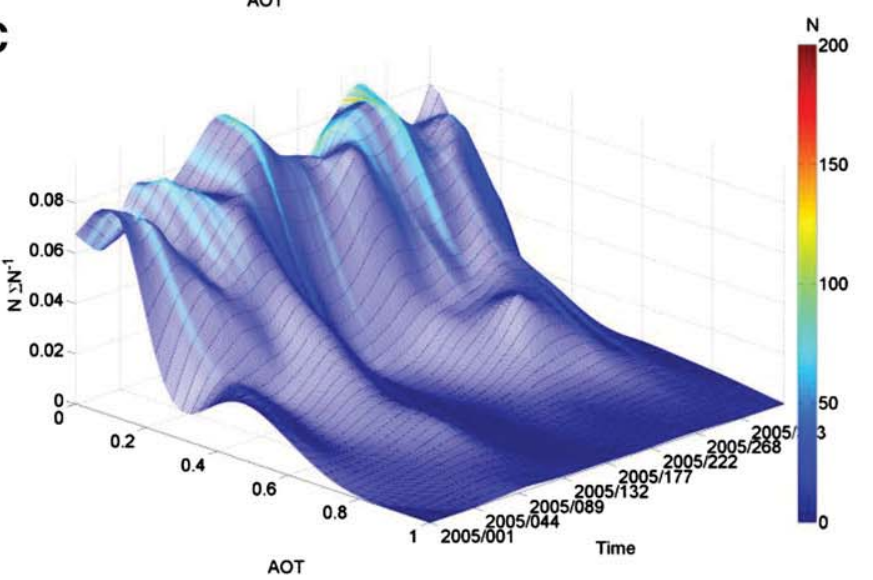

B
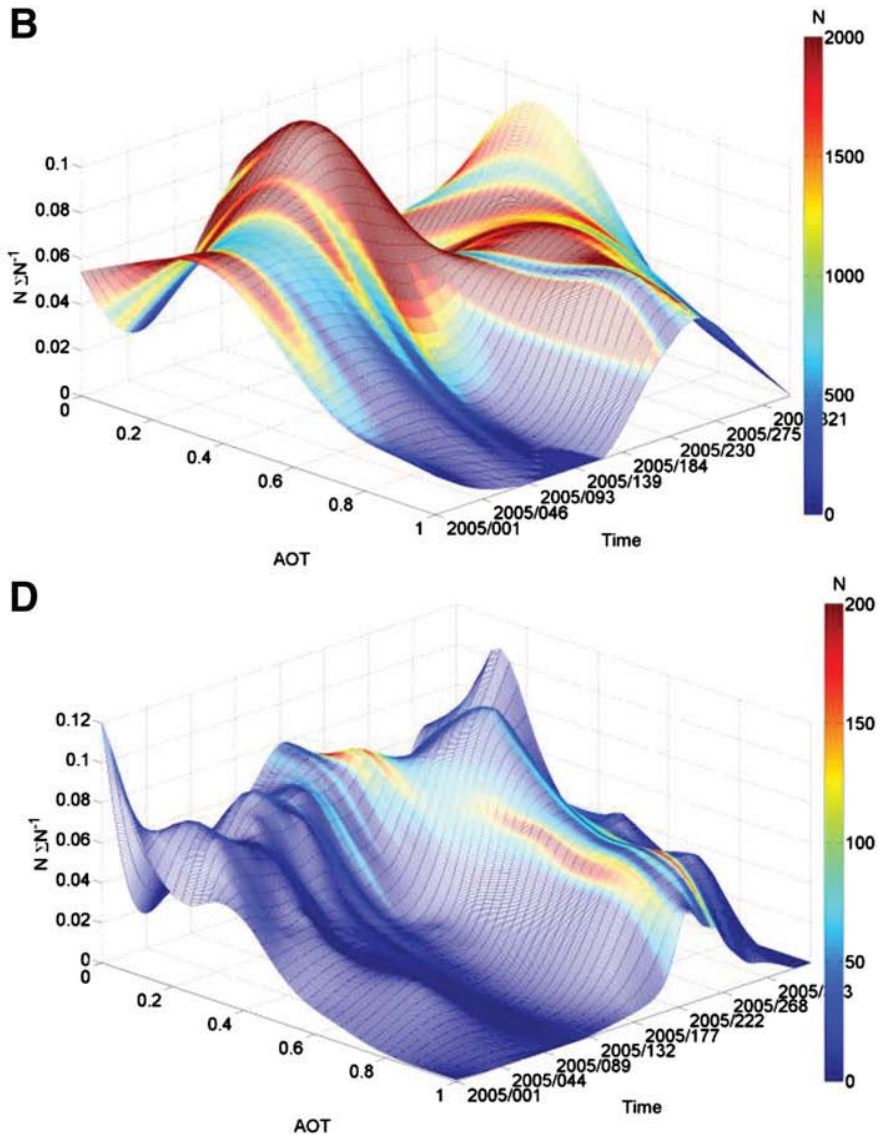

Fig. 6. Variation in aerosol optical thickness (AOT) over a northern $\left(7^{\circ} 30^{\prime} \mathrm{N}, 70^{\circ} \mathrm{W}\right.$, Figure A) and a southern $\left(7^{\circ} 30^{\prime} \mathrm{S}, 70^{\circ} \mathrm{W}\right.$, Figure B) subset of the study area ( $\mathrm{size} 500 \times 500 \mathrm{~km}{ }^{2}$ each). The $x$-axis represents the time (year 2005), the $y$-axis shows AOT bins (width 0.01) and the z-axis represents counts per AOT bin (as fraction of total number of observation at

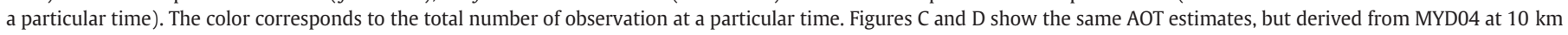
resolution. 


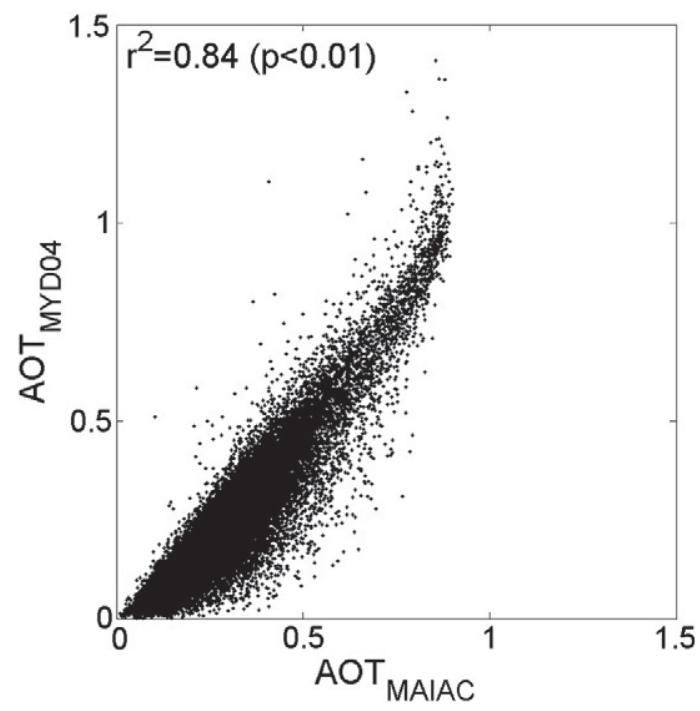

Fig. 7. Comparison between MAIAC AOT and MYD04 for the entire study area (MAIAC data were resampled to $10 \mathrm{~km}^{2}$ to match the MYD04 resolution) between 2002 and 2010, filtered by both, the MYD35 and MAIAC cloud masks.

Shown NDVI values were accumulated over an eight day period of DOY 356-364, 2010 to collect more observations, and were placed on a regular grid using $3 \mathrm{D}$ spline interpolation. While the MAIAC (Fig. 9A) and MYD09GA (Fig. 9B) processed NDVI data both captured the phenological differences between the seasonal (north) and the non-seasonal (south) forest, a much higher spatial variability of NDVI was observed from MYD09GA (Fig. 10B) compared to MAIAC (Fig. 10A). This spatial variability is not supported by changes in the land cover type (Fig. 2) or heterogeneity in tropical vegetation and is therefore indicative of the noise level discussed above. While this Figure shows only one 8-day period, we created a movie file covering the entire study area for a two-year period. This movie, which is available in the supportive online material, provides a visual demonstration of algorithm differences in assessment of the temporal variability of NDVI.

The increased noise levels limited the ability of MYD09 observations to describe shifts in vegetation greenness. This can be demonstrated when comparing the distributions of NDVI observations across a latitudinal gradient from $10^{\circ} \mathrm{N}$ to $10^{\circ} \mathrm{S}$ by binning NDVI values into strata (based on a bin width of 0.01 ) and counting the percentage of observations per bin and latitude (i.e. aggregating across all longitudes). For the non-seasonal tropical forest, the vast majority of NDVI observations are expected to be at the higher end of the scale (0.8-0.9) with little variability likely across southern latitudes, whereas seasonal vegetation in the north should show clear shifts in NDVI distributions when comparing dry and wet seasons. Fig. 11 presents NDVI distributions for one day in the northern tropics wet season (Figure $A$ and $B$ ) and a northern tropics dry season (Figure $C$ and D). Rather than absolute counts of observations, percentages of total cloud free observations are shown along the z-axis in order to normalize for latitudinal variations in cloud cover (as cloud cover drives the number of clear pixels that can be aggregated across each longitude). MAIAC observed NDVI distributions where highly consistent across all southern latitudes with values ranging between 0.7 and 0.9 (left column). A slightly lower range of NDVI values was found in the northern latitudes, due to lower vegetation cover in the tropical savannah regions (Fig. 11A, compare Fig. 1). In the north, a clear reduction in NDVI values was observed during the dry season (Fig. 11C) while distributions in the south showed little or no change. The distribution of MYD09GA data (Fig. 11B and D) was in both cases more skewed towards lower NDVI values and the relative number of high NDVI values was lower and less equally distributed across latitudes.

MYD09 processed NDVI observations were also mostly distributed around 0.7 and 0.9 across southern latitudes, however, the distribution was notably wider and skewed towards the lower range $(<0.7)$, likely because NDVI observations were depressed by the cloud and aerosol contamination. In addition, the NDVI distribution varied strongly even across southern latitudes, which is not supported by latitudinal changes in landcover and can therefore be attributed to variations in cloud and aerosol contamination. Similarly, the shifts between dry and wet season the northern latitudes are much less apparent in MYD09 compared to MAIAC, thus showing a more limited ability of MYD09 to detect seasonal changes in greenness in conditions of high cloudiness.

Finally, we also analyzed the dependence of NDVI on AOT directly, by using the two $10 \times 10 \mathrm{~km}^{2}$ sample areas earlier presented in Figs. 7 and 8. In order to eliminate potential differences due to cloud masking and quality screening and to single out the aerosol effect, data shown in Fig. 12 were filtered using both MAIAC and MYD09/ MYD35 cloud mask and quality flags. Data points acquired between 2002 and 2010 are shown; the color of the data points corresponds to the respective month of acquisition. MYD09 processed data showed a statistically significant relationship with both MAIAC and MYD04 derived AOT $\left(r^{2}=0.2 p<0.05\right.$, Fig. $12 \mathrm{~B}$ and D and $r^{2}=0.15$ $p<0.05$, Fig. $12 \mathrm{C}$ and $\mathrm{E}$ ), as high AOT values depressed NDVI observations in both northern and southern sites. The random distribution of the color codes shows that this dependence cannot be explained by seasonality of NDVI and AOT, suggesting a relatively high aerosol effect on MYD09 NDVI. MAIAC NDVI showed only a weak AOT dependence in both regions, which was not, however, statistically significant at $p<0.05$ (Figures A and D).

\section{Discussion}

This study presented a comparative analysis between the currently operational and a new atmospheric correction algorithm MAIAC to monitor the vegetation status in tropical regions from MODIS data. We have shown that cloud screening and correction for aerosols are critical for reducing uncertainties of remote sensing of vegetation over tropical regions which confirms results obtained by other groups (Di Rosa et al., 2009). For instance, Figs. 8 and 9 suggest that cloud leakage was the single most important factor driving high spatial and temporal variability in MYD09GA derived NDVI. The time series approach implemented in MAIAC helped to significantly reduce these uncertainties as it was able to detect clouds more reliably while providing a significantly larger amount of cloud free observations. This resulted in MAIAC showing stable and well-reproducible patterns in vegetation greenness with errors and uncertainties reduced by a factor of up to ten compared to current state-of-the-art retrievals.

While we did not conduct a detailed analysis here, the main improvement in MAIAC cloud screening is probably achieved for low and thin or small (sub-pixel) clouds, which are partly captured by the MAIAC aerosol retrievals (Lyapustin et al., 2011b, 2012) but otherwise are hard to detect using conventional spectral or brightness temperature tests. It has been a common land community practice to mitigate the effect of missed clouds by compositing data over 8-day (MYD09A1) or 16-day periods (MYD13A2). This effectively implements an additional cloud filter, as values with lower reflectance are preferred over higher reflectance values, thereby eliminating data with a higher potential for cloud contamination. Our results presented in Figs. 2, 8 and 9, show that while this technique helped to reduce $\sigma$ somewhat, the composited data still showed high levels of uncertainties over the study area, making analysis of vegetation greenness or trend predictions over Amazônia challenging. For instance, obtaining accurate results from conventional MODIS products 
A

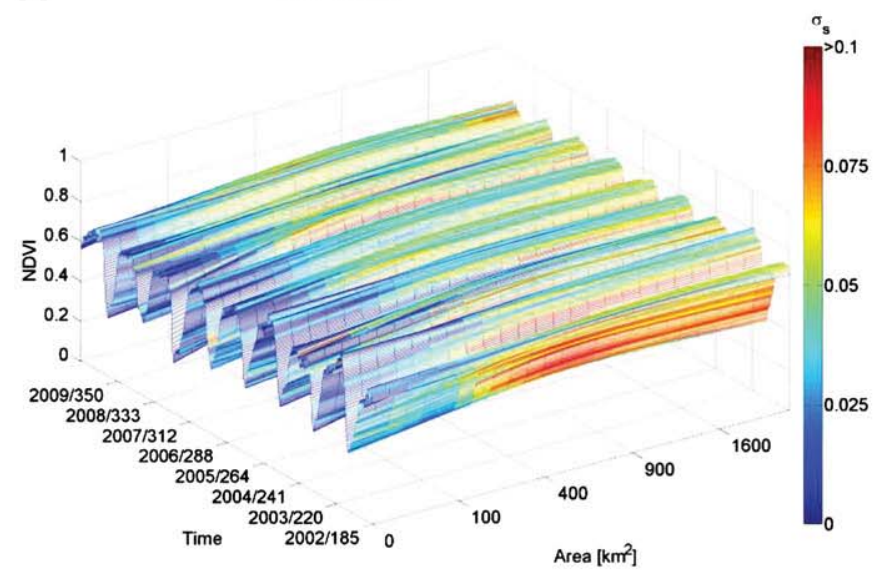

\section{MYD09 with MAIAC cloud mask}
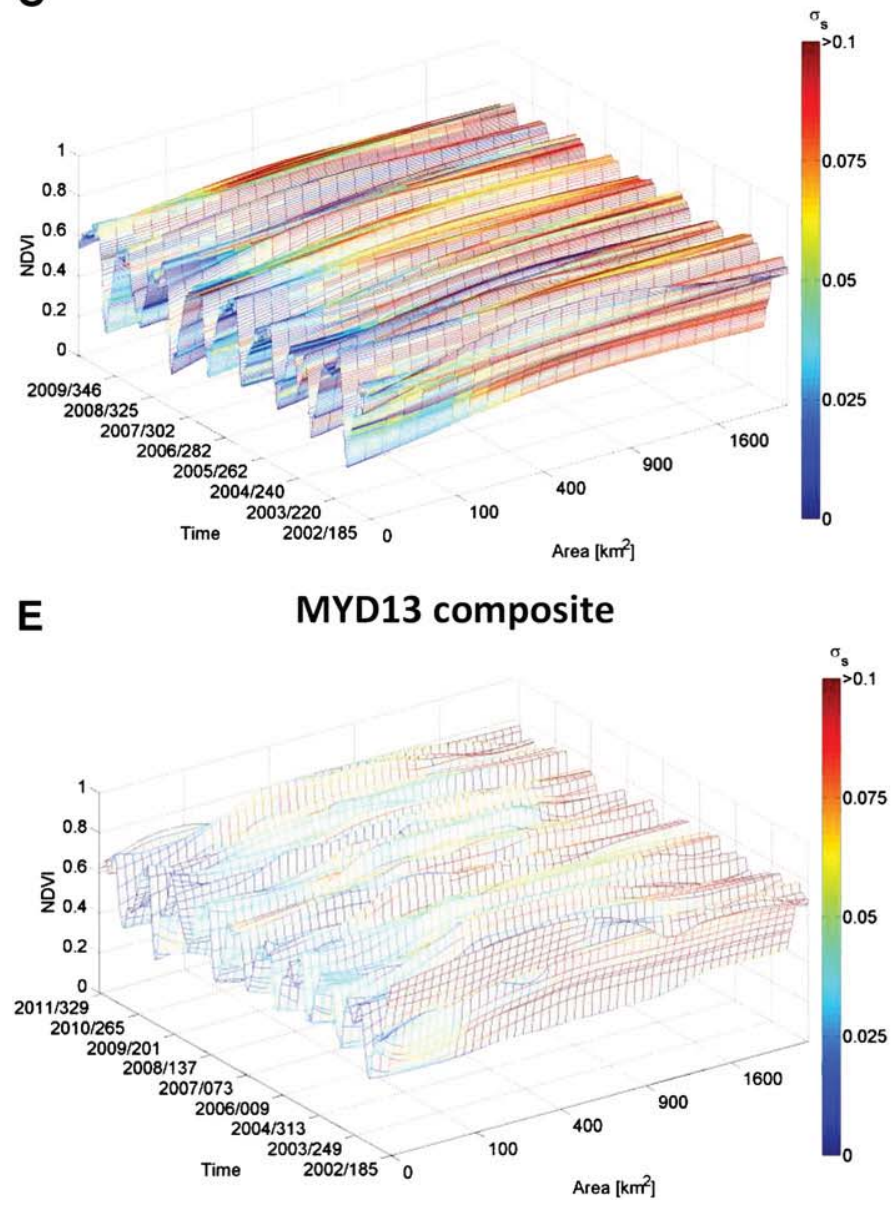

B MYD09GA

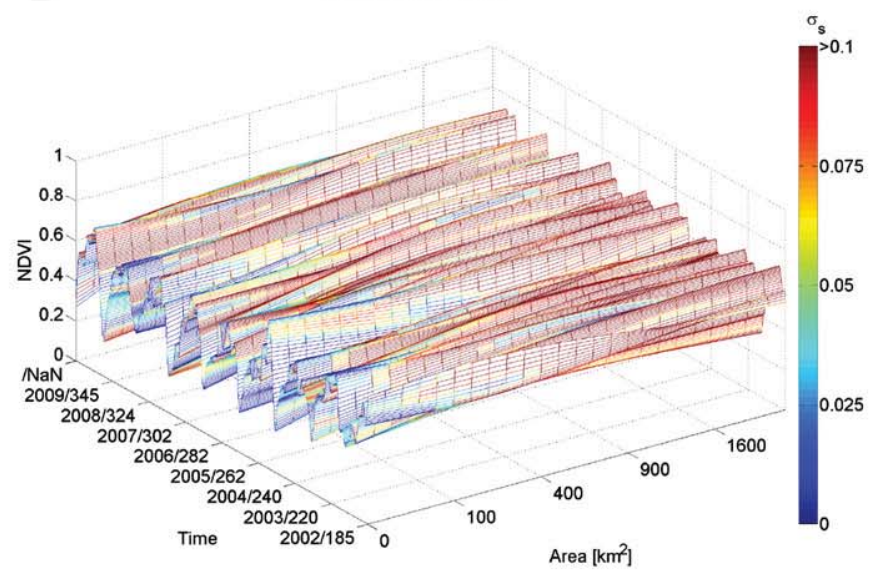

D MYD09A1 composite

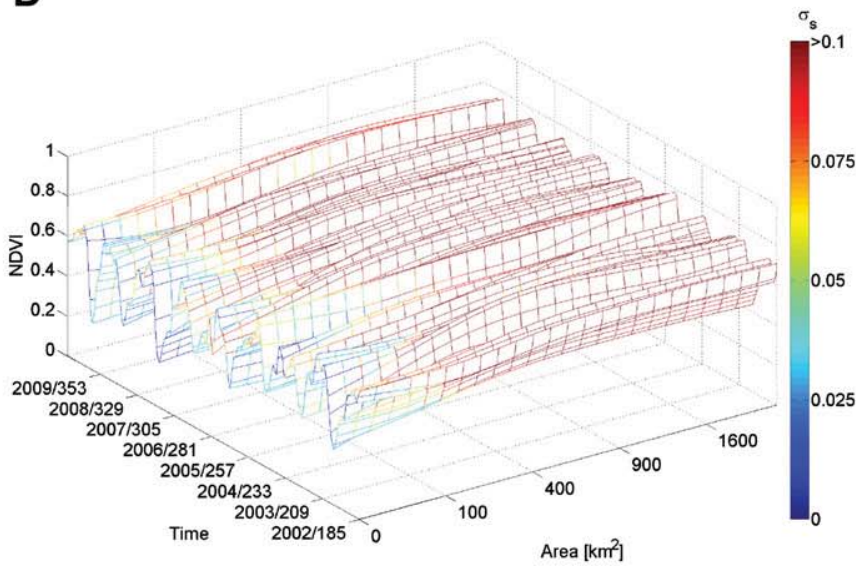

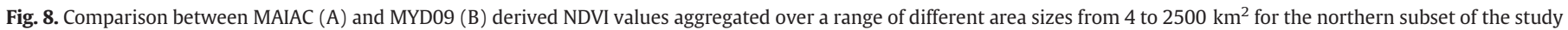
area $\left(7^{\circ} 30^{\prime} \mathrm{N}, 70^{\circ} \mathrm{W}\right)$. The $\mathrm{x}$-axis shows the size of the aggregated area (pixel), the $y$-axis represents the time (2002-2010) the $z$-axis shows the corresponding NDVI value. The color of the surface corresponds to the standard deviation obtained from averaging over different areas. Figure C shows MYD09 derived data, but using the MAIAC cloud mask. Figure D shows the same product derived from the 8 day MYD09A1 composite, Figure E represents the MYD13A2 16 day product. Please note that the number of observations for these composites is less compared to the daily products.

(MYD09GA, MYD09A1, MYD13) requires large statistics and very skillful and sophisticated data filtering approach (e.g., Samanta et al., 2012).

While additional data quality analysis and filtering may improve the results, it also substantially reduces the amount of information. For instance, composited data yielded better results than the daily MODIS products (Figs. 2, 8, 9, A1, A2) but less than half as many pixels were observed over a 16 day period than observed by MAIAC (see for instance Fig. A3) over the same period of time, not including the higher number of MAIAC observations for the same pixels during the compositing period. Compared to the standard product outputs, the MAIAC derived cloud mask yielded on average about $25 \%$ more cloud free observations, which is a significant gain considering that between $75 \%$ and $99 \%$ of the images was covered by clouds at any 
A

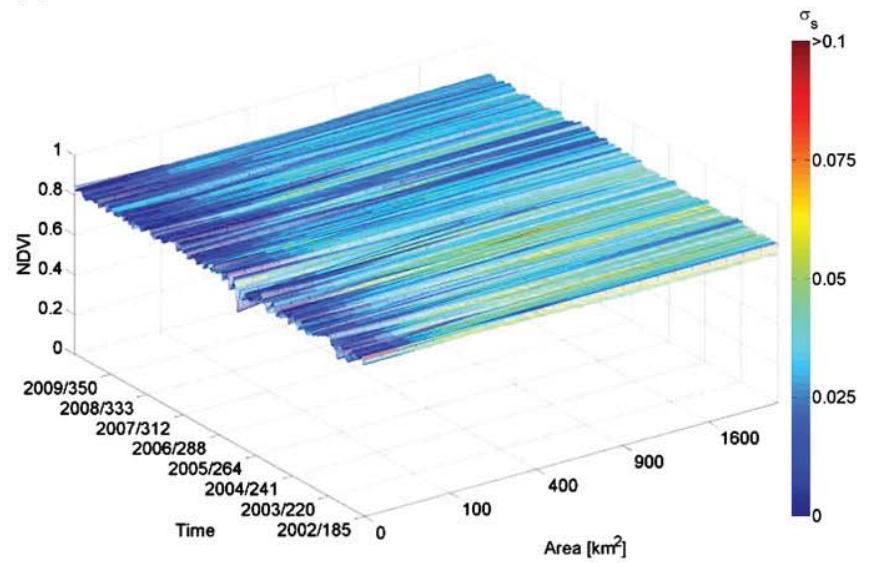

C MYD09 with MAIAC cloud mask

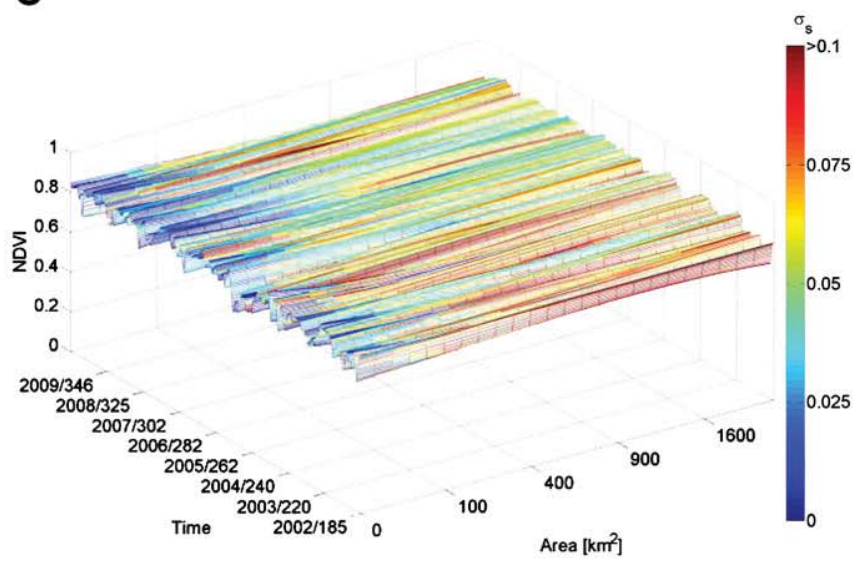

E

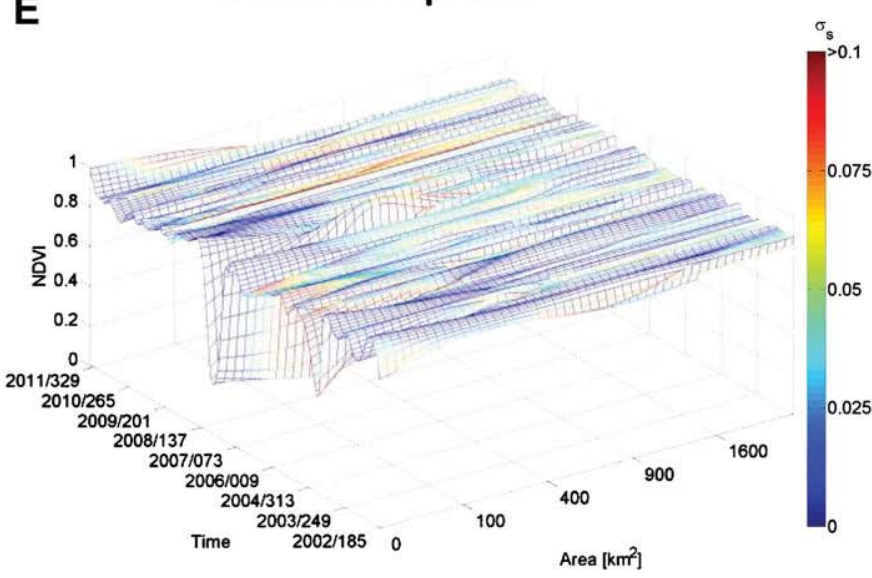

B MYD09GA

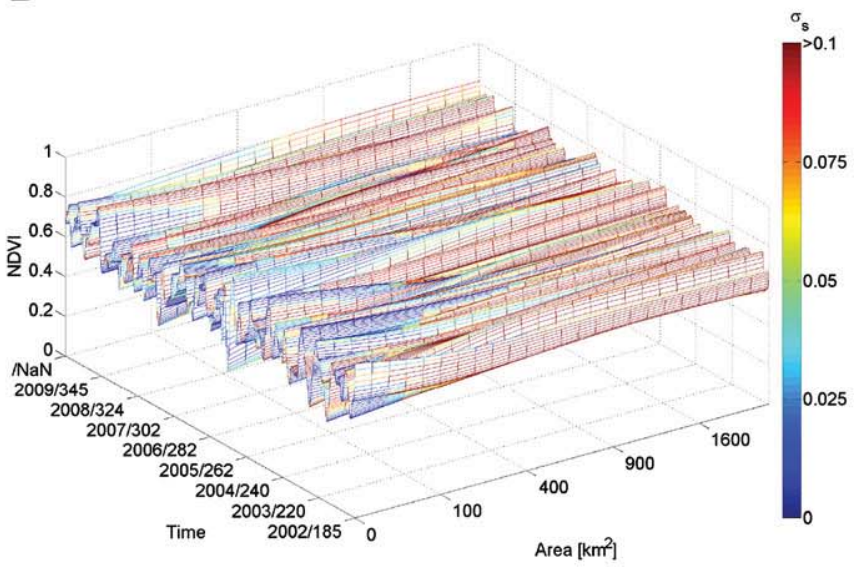

MYD09A1 composite

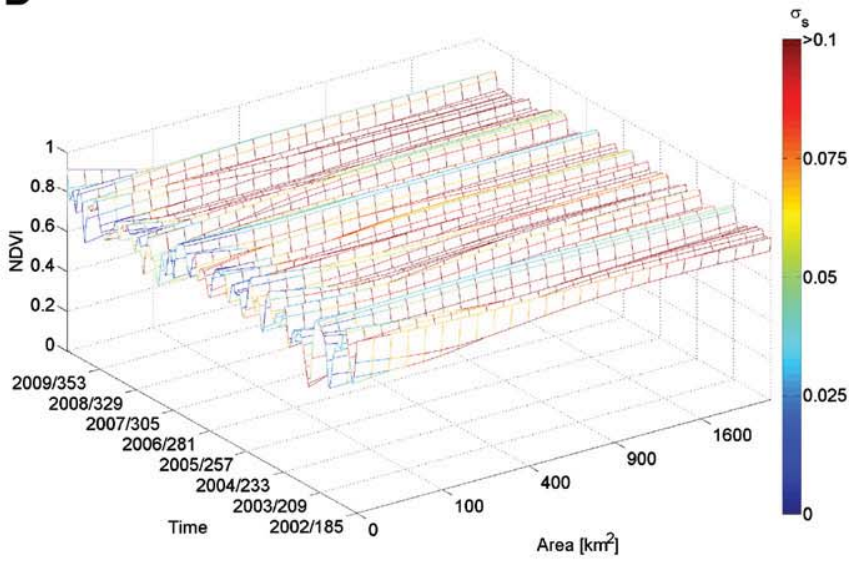

Fig. 9. Comparison between MAIAC (A) and MYD09 (B) derived NDVI values aggregated over a range of different area sizes from 4 to $2500 \mathrm{~km}{ }^{2}$ for the southern subset of the study area $\left(7^{\circ} 30^{\prime} \mathrm{S}, 70^{\circ} \mathrm{W}\right)$. The $x$-axis shows the size of the aggregated area (pixel), the $y$-axis represents the time (2002-2010), the $z$-axis shows the corresponding NDVI value. The color of the surface corresponds to the standard deviation obtained from averaging over different areas. Figure C shows MYD09 derived data, but using the MAIAC cloud mask. Figure D shows the same product derived from the 8 day MYD09A1 composite, Figure E represents the MYD13A2 16 day product.

given time. The potential for increasing the number of cloud free observations is an important finding, as it can help to enhance the frequency of satellite based assessment of forest loss and landscape disturbance over tropical regions (Hansen et al., 2008, 2009) and allow more timely and accurate predictions of the status of the remaining tropical forest.
Consistent with previous work, our results have shown that atmospheric effects can depress NDVI observations (Myneni \& Asrar, 1994; Xiao et al., 2003). The relationship between AOT and MYD09 NDVI presented in Fig. 12 suggest that MYD09GA collection 5 surface reflectance contained residual atmospheric effects as both northern and southern study sites showed a noticeable AOT-dependence of 
A

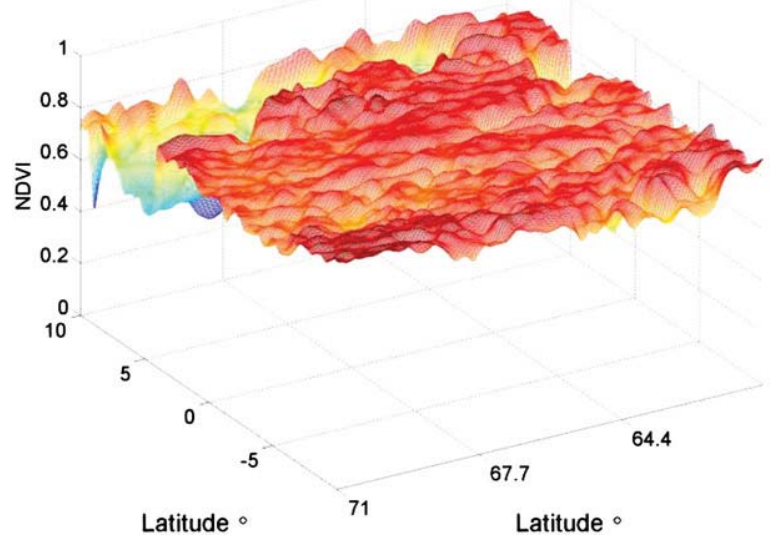

B MYD09GA

2010/364

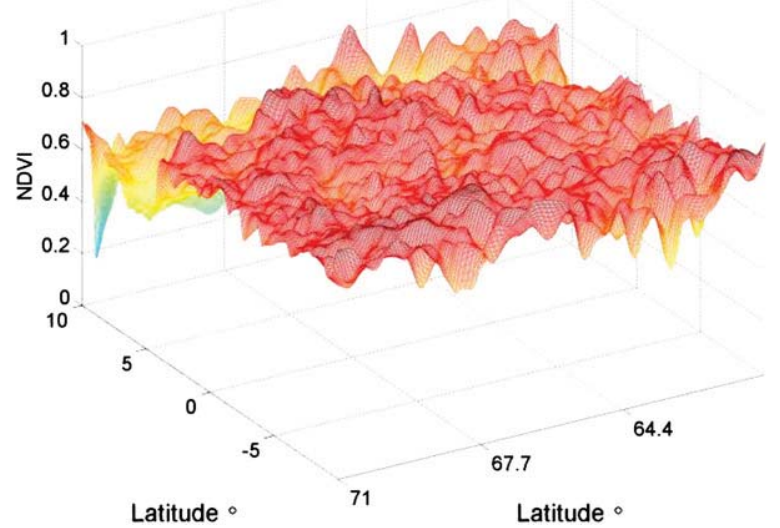

Fig. 10. Spatial distribution of NDVI over the entire study area using NDVI observations processed with MAIAC (A) and MYD09 (B) acquired over a 10 day period between DOY 355 and DOY 364, 2010. The $x$ - and $y$-axis represent geographical longitude and latitude, respectively, the $z$-axis shows NDVI. A three dimensional spline function has been fitted through all valid NDVI observation acquired by either algorithm over the 10 day period to obtain a continuous surface from the discrete observations.

A

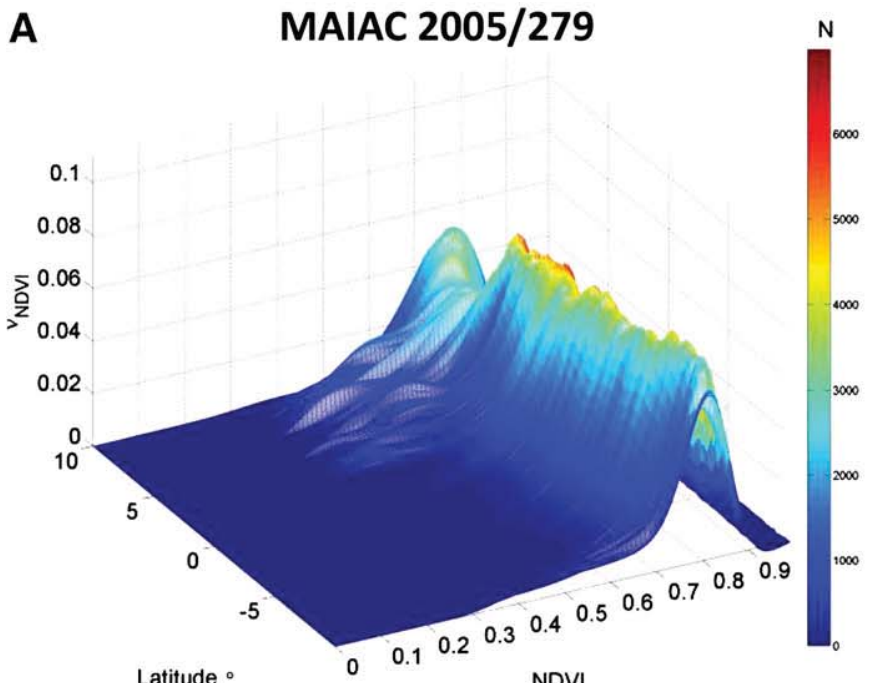

C
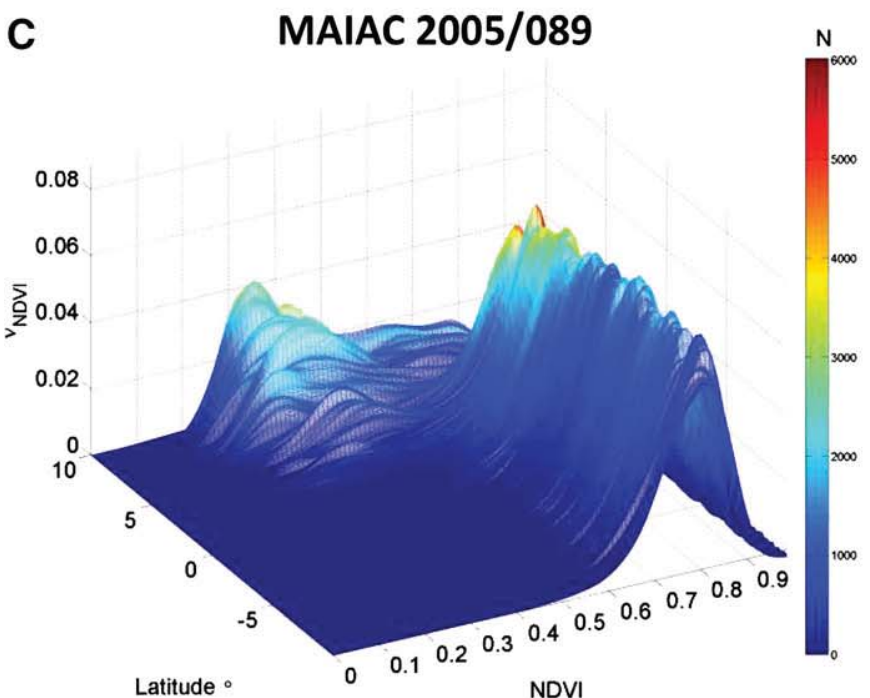

B
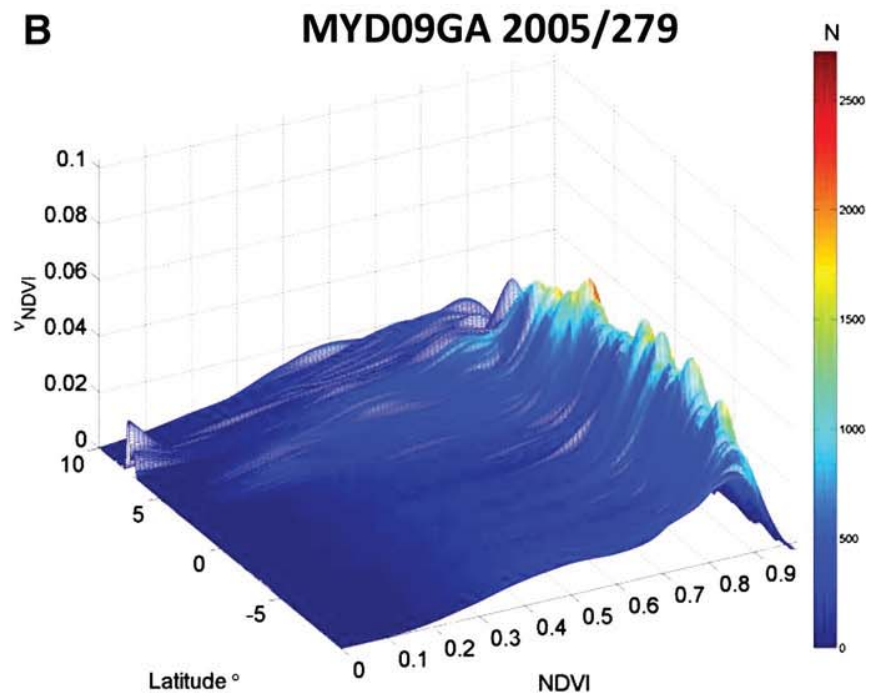

D

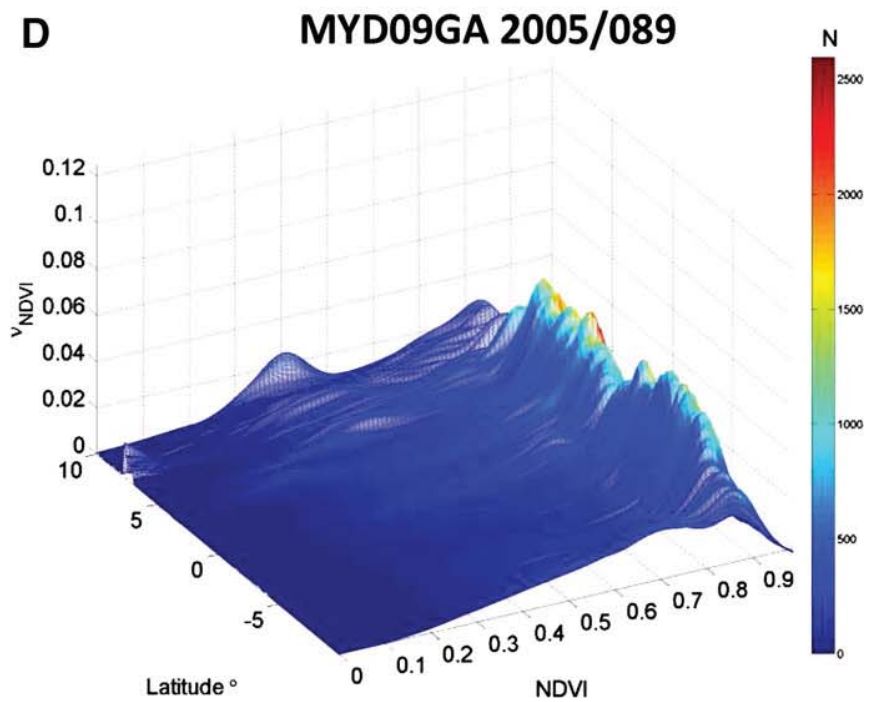

Fig. 11. Distribution of NDVI across a latitudinal gradient from $10^{\circ} \mathrm{S}$ to $10^{\circ} \mathrm{S}$ for a day in late northern latitude summer (top row) and late northern latitude winter (bottom row). The $x$-axis represents NDVI bins (bin size $=0.01$ ), the $y$-axis shows the latitudinal range. The $z$-axis represents NDVI observations per bin (aggregated across all longitudes, data are shown as fraction of the total number of observations at a particular latitude). The left column (Figure A and C) shows MAIAC derived data, the right column (Figures B and D) shows MYD09 derived observations. The total number of observations per bin is indicated by the color. 

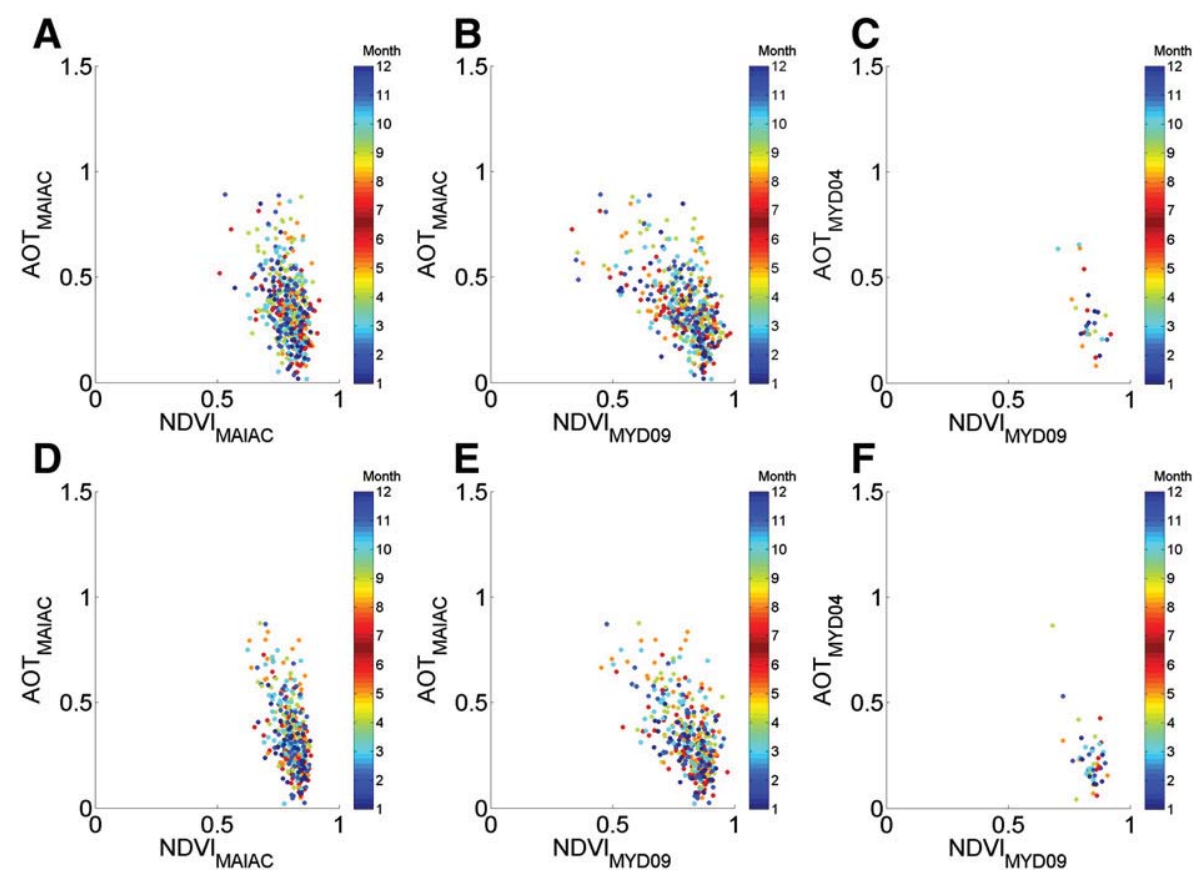

Fig. 12. Relationship between NDVI and MAIAC derived aerosol optical thickness (AOT) at a northern $\left(7^{\circ} 30^{\prime} \mathrm{N}, 70^{\circ} \mathrm{W}\right)$ and a southern $\left(7^{\circ} 30^{\prime} \mathrm{S}, 70^{\circ} \mathrm{W}\right)$ subset of the study area $($ size $100 \mathrm{~km}^{2}$ each). The left column (Figure A and D) shows MAIAC processed observations, the central column (Figure B and E) shows NDVI obtained from MYD09 and AOT derived from MAIAC. The right column (Figure C and F) shows MYD09 derived NDVI compared to MYD04 derived AOT. Data acquired over the full 8 year period are shown (2002-2010). The marker color corresponds to the month of acquisition as indicated by the bars on the right.

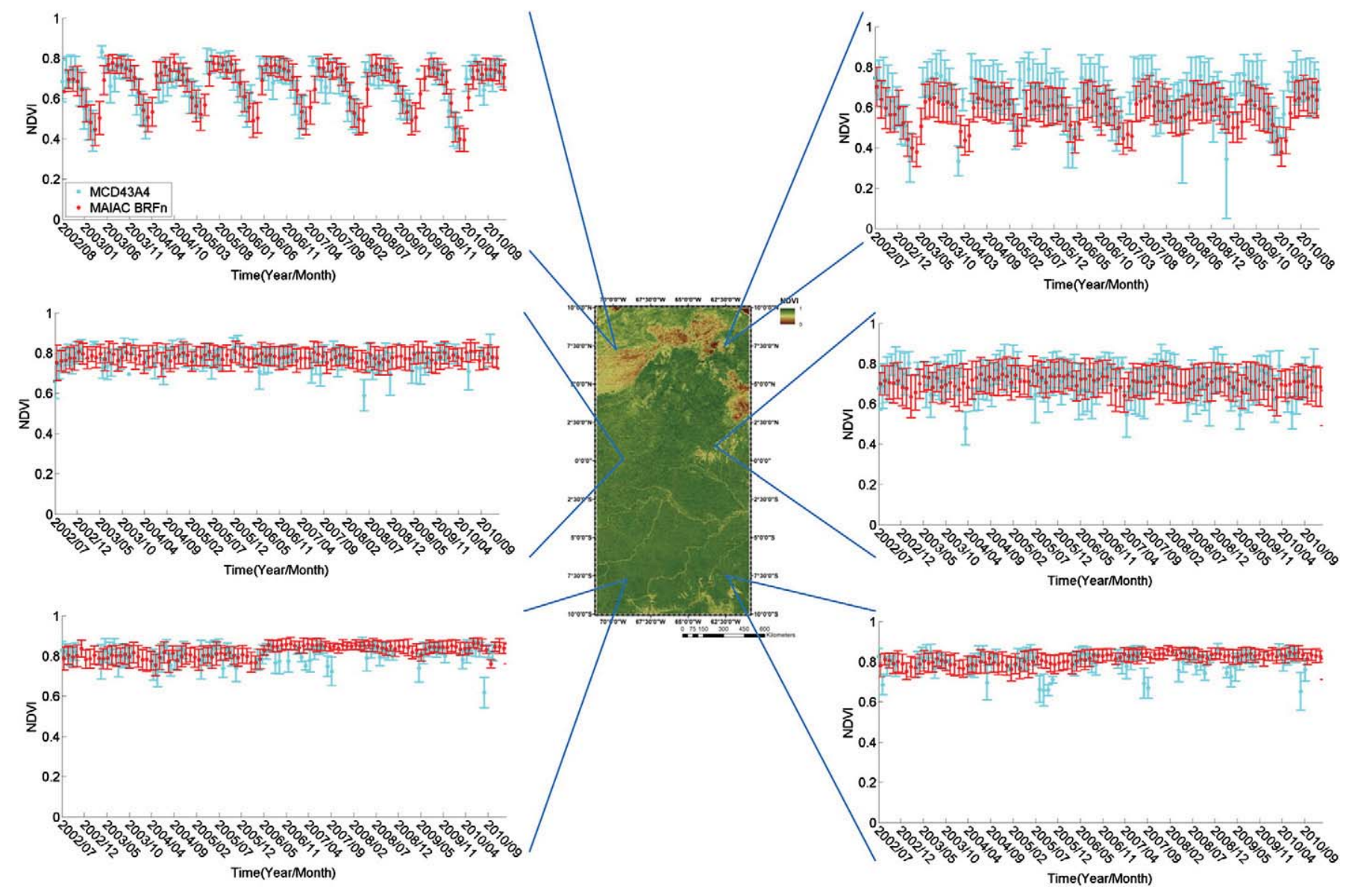

Fig. A1. Monthly observations of NDVI from MCD43A4 (1 km 16-day NBAR view angle normalized), and MAIAC BRFn obtained over a $50 \times 50 \mathrm{~km}$ area as indicated in the map. The errorbars represent the mean spatial variability over the $50 \times 50 \mathrm{~km}$ subset (Please note that the points and errorbars of the products are slightly offset from each other for purposes of readability). 
A

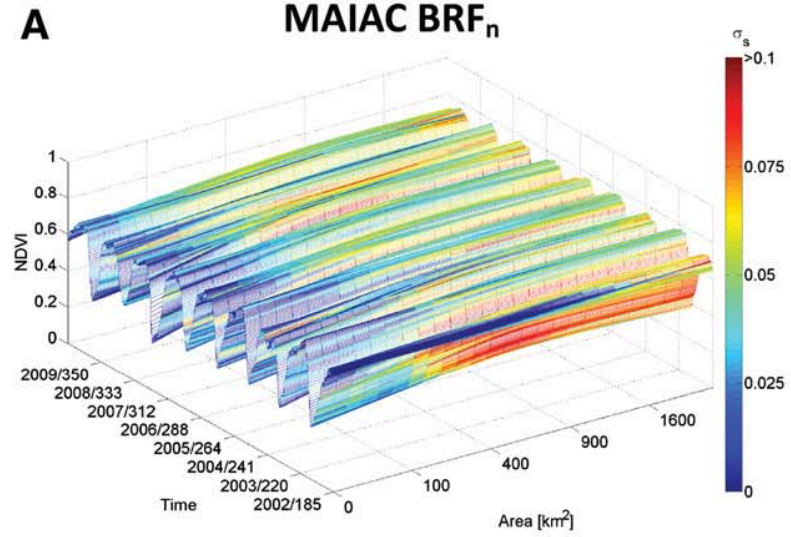

C

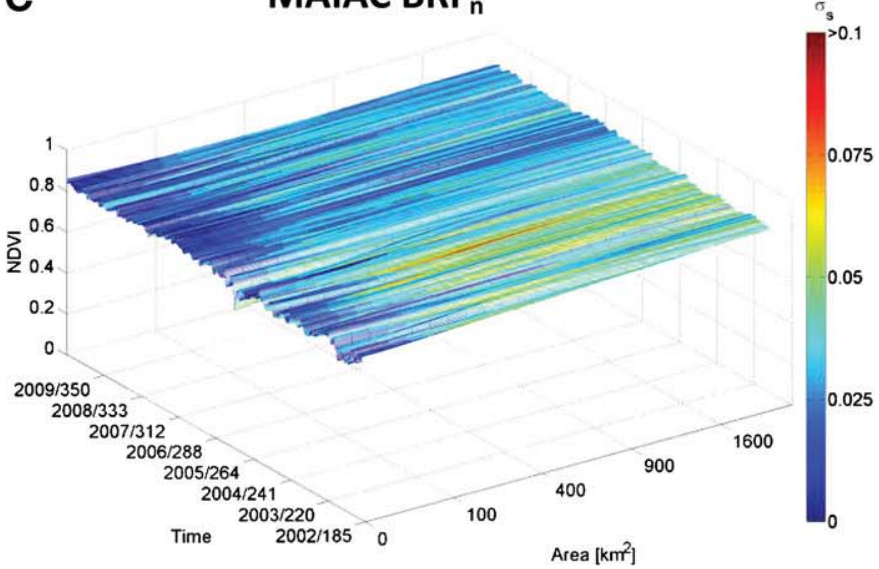

B
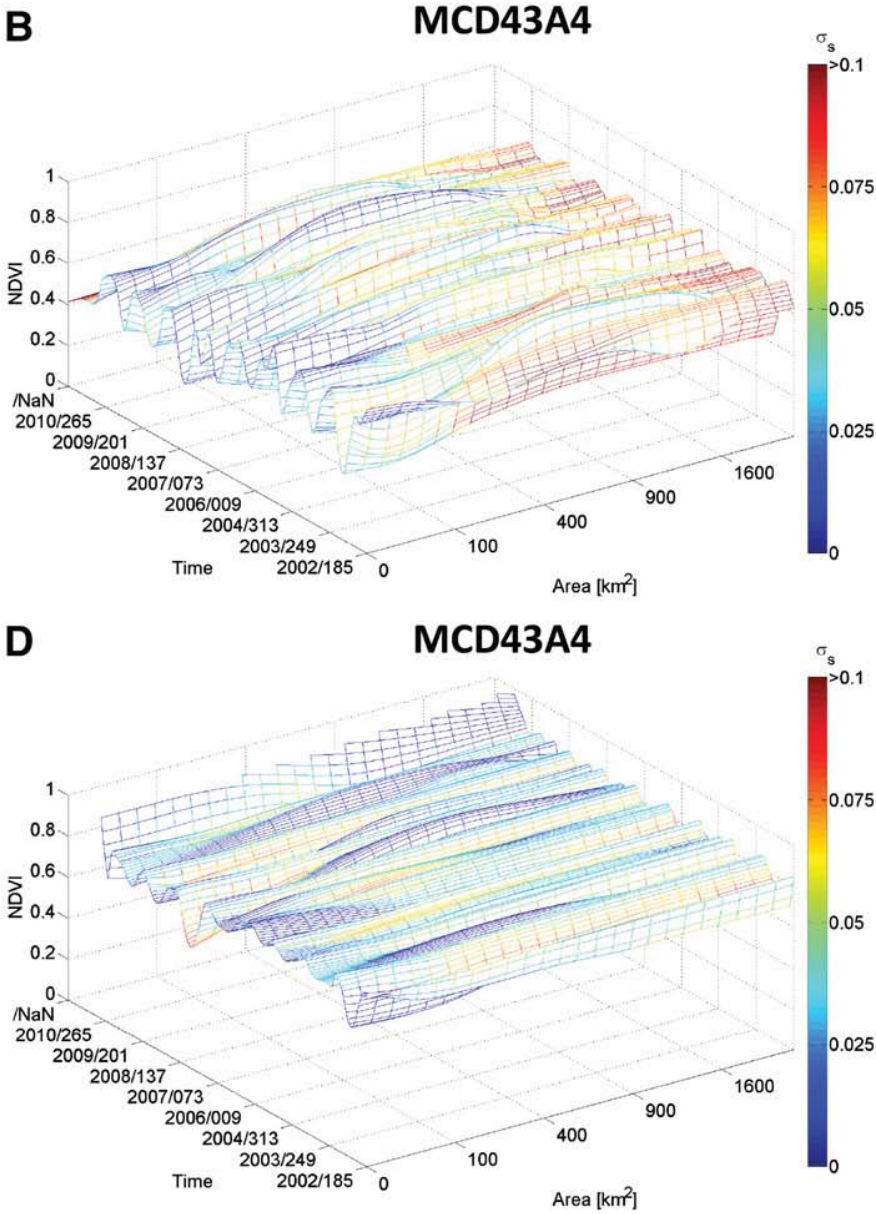

Fig. A2. Comparison between MAIAC BRFn (left column A, C) and MCD43A4 (right column B,D) derived NDVI values aggregated over a range of different area sizes from 4 to $2500 \mathrm{~km}^{2}$ for the northern $\left(7^{\circ} 30^{\prime} \mathrm{N}, 70^{\circ} \mathrm{W}\right.$, top row) and southern subset of the study area $\left(7^{\circ} 30^{\prime} \mathrm{S}, 70^{\circ} \mathrm{W}\right.$, bottom row). The $\mathrm{x}$-axis shows the size of the aggregated area (pixel), the $y$-axis represents the time (2002-2010) the $z$-axis shows the corresponding NDVI value. The color of the surface corresponds to the standard deviation obtained from averaging over different areas.

MYD09 NDVI. Partly, it can be explained by the Lambertian surface assumption used in MYD09, which does not discriminate between the direct and diffuse irradiance, the effective surface reflectance for which is different. The relative amount of direct vs. diffuse radiative flux at the surface depends on the aerosol amount and path through the atmosphere (solar and view zenith angle). This causes biases in the surface reflectance which are dependent on the viewing geometry and AOT even with perfect knowledge of AOT (Lyapustin, 1999; Wang et al., 2010).

This study has shown that MAIAC algorithm can yield dramatically enhanced estimates of commonly derived vegetation indices such as NDVI over tropical regions. As a result, MAIAC may allow new opportunities for re-assessing the state of terrestrial ecosystems even in very cloudy regions like the Amazon and could ultimately help to

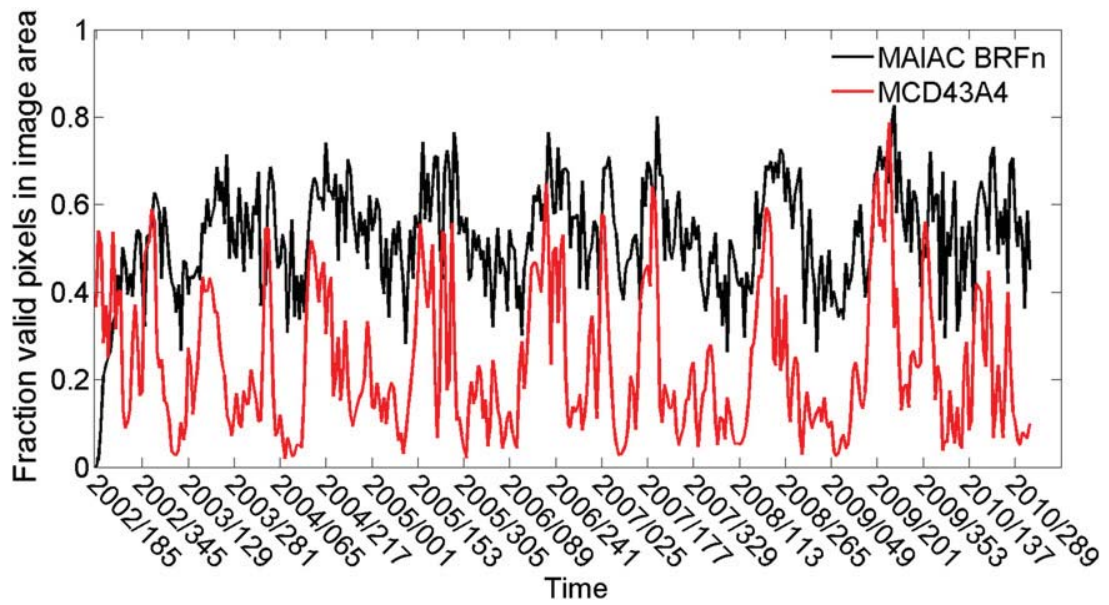

Fig. A3. Comparison between the fraction of cloud free, high quality pixels, acquired from MAIAC (black) and MCD43A4 (red). MAIAC observations have been aggregated to 16 day periods to meet the temporal scales of MCD43A4. 
reduce uncertainties of terrestrial vegetation products globally. It should be noted that differences between MAIAC and MODIS standard processing will likely be considerably smaller in temperate ecosystems, as cloud masking is most challenging in tropical regions with warm, low clouds that are difficult to detect using conventional techniques. More research will be required to determine the magnitude of this effect in other regions of the globe. Nonetheless, the quality of MAIAC demonstrated in tropical ecosystem clearly demonstrates its potential for accurate cloud detection and aerosol correction.

As cloud cover is seasonally dependent, it seems plausible that previously reported increases in Amazon greenness during a drought could, at least in part, result from reduced cloudiness, rather than from a change in vegetation status. More research will be required to investigate this possibility but considerable uncertainties in standard products found in this study highlight the need for alternative processing techniques over tropical regions (Zelazowski et al., 2011). The results of this study suggest that MAIAC could provide an alternative for reassessment of biophysical changes over tropical rainforests.

\section{Acknowledgements}

This research was supported by funding from the NASA Terrestrial Ecology Program (Dr. D. Wickland). The anonymous reviewers are thanked for their helpful and constructive criticism.

\section{Appendix A. Comparison of BRDF normalized products}

In order to investigate the effect of BRDF on MODIS derived NDVI, we compared directionally normalized NDVI from the MODIS standard product and MAIAC for the same two MODIS tiles (h11v09 and h11v08) and time period (2002-2010) (Fig. 1). For that, we used MAIAC normalized reflectance $\mathrm{BRF}_{n}$ and MODIS NBAR (nadir BRDF-adjusted reflectance) product. The $\mathrm{BRF}_{\mathrm{n}}$ is normalized to the fixed geometry of solar zenith angle $\left(\theta_{s}\right)$ of $45^{\circ}$ and nadir view using the RTLS model:

$$
\mathrm{BRF}_{n}=\frac{\mathrm{BRF} \times \operatorname{RTLS}\left(\theta_{s}, \theta_{v}, \Delta \varphi\right)}{\operatorname{RTLS}\left(\theta_{s}=45^{\circ}, \theta_{v}=0^{\circ}, \Delta \varphi=0^{\circ}\right)},
$$

where $\theta_{v}$ and $\Delta \varphi$ are view zenith and relative azimuth angle, respectively.

The MCD43A4 product is a 16 day composite product which provides level-3 gridded surface reflectance at a 0.5 -kilometer resolution adjusted for view angle effects using the bidirectional reflectance distribution function (BRF). MCD43A4 data and corresponding quality flags (MCD43A2) were obtained from the EOS data gateway and quality filters were applied as stated in Table 1 . While MCD43A4 and MAIAC BRF $_{\mathrm{n}}$ are both BRDF normalized datasets, there are two differences between them: First, MCD43A4 is normalized in the view angle only, while MAIAC BRF $\mathrm{n}_{\mathrm{n}}$ is normalized in both view and solar zenith angles. Second, MCD43A4 is a 16-day composite product based on both Terra and Aqua MODIS data, while MAIAC BRF ${ }_{n}$ is daily reflectance, here from the Aqua platform only. Fig. A1 shows NDVI time series from the same $50 \times 50 \mathrm{~km}^{2}$ subsets as used before but comparing MCD43A4 to MAIAC BRF $n$ at monthly time steps. As for the non-normalized data, we computed monthly mean values for each pixel by averaging all valid (that is cloud screened, and quality filtered) pixels acquired during that month and obtained mean and standard deviation by averaging these monthly values across each $50 \times 50 \mathrm{~km}^{2}$ block. Differences observed between the 16 day product MCD43A4 and daily MAIAC BRF ${ }_{n}$ were moderate for the most part, however, cloud cover caused residual outliers in the 16 day product, with some areas more affected than others. As opposed to conventional composite, MCD43A4 reflectance relies on daily MOD09 observations to retrieve BRDF and is also affected by undetected clouds, especially if the total number of observations is low. Overall the performance of the 16 day NBAR composite product was similar to that of the 16 day VI product (MYD13).

Fig. A2 shows NDVI estimates (along z-axis) as a function of time during 2002-2010 ( $x$-axis). The $y$-axis shows the spatial variability of NDVI when averaging over different areas, from $2 \times 2$ to $50 \times 50 \mathrm{~km}^{2}$. The color represents the standard deviation $(\sigma)$ of the spatially averaged NDVI estimates, the areas correspond to the non-normalized data presented in Figs. 8 and 9. MAIAC BRF $_{n}$ observations are shown in Figures A (northern, seasonal region), and Figure C (southern, non- seasonal part), the corresponding MCD43A4 observations are given in Figures B and D. Compared to the non-normalized MAIAC product, MAIAC derived $\mathrm{BRF}_{\mathrm{n}}$ observations showed similar levels of uncertainty indicating only a limited effect of BRDF on NDVI reflectance (compare Figs. 8A and 9A). The MODIS NBAR product yielded comparatively overall larger uncertainties across the examined scales with individual dates showing considerable offsets, which were likely driven by undetected clouds.

The number of observations shown for the NBAR product was considerably lower than for MAIAC observations. Fig. A3 shows the proportion of cloud free pixels from MCD43A4. To match the temporal scale of MCD43A4, MAIAC data were aggregated over 16 days.

In summary, this analysis showed little difference between MAIAC BRDF normalized and non-normalized NDVI which agrees with results from Lyapustin et al. (this issue). MAIAC NDVI obtained from $\mathrm{BRF}$ and from $\mathrm{BRF}_{\mathrm{n}}$ were found to be very similar with only slight reduction in variability. As NDVI is typically high in tropical forests, the red reflectance constitutes only a small fraction of the NIR signal, thereby canceling most of the anisotropy in NDVI (but not so in the reflectance). In addition, the anisotropy gets reduced as the surface becomes brighter due to multiple scattering and consequently the relative anisotropy of the NIR reflectance is lower than that of the red reflectance.

The results presented in Figs. A1 and A2 show that despite additional BRDF-based cloud masking in MCD43A4, cloud leak remains problematic in this product. While the BRDF retrieval in MCD43 helped filter residual clouds, when enough clear sky observations for reliable BRDF inversion were available, this method does not allow the cloud mask error to be separated from the total error budget. In cases of high cloudiness, residual clouds can lead to wrong BRDF retrievals, and, as a result, the MCD43A4 BRDF-normalization may increase the total error of surface reflectance (or NDVI) rather than decreasing it. It should also be noted that the results presented in Fig. A1 show monthly-mean values over large areas $\left(2500 \mathrm{~km}^{2}\right)$. Acquisitions at finer temporal or spatial scales using MCD43A4 would be problematic due to a lack of sufficient observations (see for instance Figs. A2, A3).

\section{Appendix B. Supplementary data}

Supplementary data to this article can be found online at http:// dx.doi.org/10.1016/j.rse.2012.08.035.

\section{References}

Ackerman, S. A., Strabala, K., Menzel, W. P., Frey, R. A., Moeller, C. C., \& Guclusteringey, L. E. (1998). Discriminating clear-sky from cloud with MODIS. Journal of Geophysical Research, 103, 141-157.

Atkinson, P. M., Dash, J., \& Jeganathan, C. (2011). Amazon vegetation greenness as measured by satellite sensors over the last decade. Geophysical Research Letters, 38 , L19105.

Di Rosa, D., Notarnicola, C., Posa, F., \& Ieee (2009). Cross-comparison and validation of modis aqua cloud mask by using cloudsat and calipso datasets. 2009 IEEE International Geoscience and Remote Sensing Symposium, Vols. 1-5. (pp. 2321-2324).

Dirzo, R., \& Raven, P. H. (2003). Global state of biodiversity and loss. Annual Review of Environment and Resources, 28, 137-167.

Forster, P., \& Ramaswamy, V. (Eds.). (2007). Changes in atmospheric constituents and in radiative forcing. Cambridge, U. K.: Cambridge Univ. Press. 
Frey, R. A., Ackerman, S. A., Liu, Y., Strabala, K. I., Zhang, H., Key, J. R., \& Wang, X. (2008) Cloud detection with MODIS. Part I: Improvements in the MODIS cloud mask for collection 5. Journal of Atmospheric and Oceanic Technology, 25, 1057-1072.

Gedney, N., \& Valdes, P. J. (2000). The effect of Amazônian deforestation on the northern hemisphere circulation and climate. Geophysical Research Letters, 27, 3053-3056.

Hansen, M. C., Shimabukuro, Y. E., Potapov, P., \& Pittman, K. (2008). Comparing annual MODIS and PRODES forest cover change data for advancing monitoring of Brazilian forest cover. Remote Sensing of Environment, 112, 3784-3793.

Hansen, M. C., Stehman, S. V., Potapov, P. V., Arunarwati, B., Stolle, F., \& Pittman, K. (2009). Quantifying changes in the rates of forest clearing in Indonesia from 1990 to 2005 using remotely sensed data sets. Environmental Research Letters, 4, 034001.

Kaufman, Y. J., Wald, A. E., Remer, L. A., Gao, B. C., Li, R. R., \& Flynn, L. (1997). The MODIS 2.1-mu $\mathrm{m}$ channel - Correlation with visible reflectance for use in remote sensing of aerosol. IEEE Transactions on Geoscience and Remote Sensing, 35, 1286-1298.

Levy, R. C., Remer, L. A., Kleidman, R. G., Mattoo, S., Ichoku, C., Kahn, R., \& Eck, T. F. (2010). Global evaluation of the Collection 5 MODIS dark-target aerosol products over land. Atmospheric Chemistry and Physics, 10, 10399-10420.

Levy, R. C., Remer, L. A., Mattoo, S., Vermote, E. F., \& Kaufman, Y. J. (2007). Second-generation operational algorithm: Retrieval of aerosol properties over land from inversion of moderate resolution imaging spectroradiometer spectral reflectance. Journal of Geophysical Research-Atmospheres, 112, D13211.

Lewis, S. L., Brando, P. M., Phillips, O. L., van der Heijden, G. M. F., \& Nepstad, D. (2011). The 2010 Amazon drought. Science, 331, 554-554.

Li, W. H., Fu, R., \& Dickinson, R. E. (2006). Rainfall and its seasonality over the Amazon in the 21st century as assessed by the coupled models for the IPCC AR4. Journal of Geophysical Research-Atmospheres, 111, D02111.

Lu, D., \& Weng, Q. (2007). A survey of image classification methods and techniques for improving classification performance. International Journal of Remote Sensing, 28, 823-870.

Lyapustin, A. I. (1999). Atmospheric and geometrical effects on land surface albedo. Journal of Geophysical Research, 104, 4123-4143.

Lyapustin, A., \& Knyazikhin, Y. (2001). Green's function method for the radiative transfer problem. I. Homogeneous non-Lambertian surface. Applied Optics, 40, 3495-3501.

Lyapustin, A., Martonchik, J., Wang, Y., Laszlo, I., \& Korkin, S. (2011a). Multi-angle implementation of atmospheric correction (MAIAC): Part 1. Radiative transfer basis and look-up tables. Journal of Geophysical Research, 116, D03210. http://dx.doi.org/ 10.1029/2010JD014985.

Lyapustin, A., \& Wang, Y. (2009). The time series technique for aerosol retrievals over land from MODIS. In A. Kokhanovky, \& G. De Leeuw (Eds.), Satellite aerosol remote sensing over land (pp. 69-99). Springer Praxis Books.

Lyapustin, A., Wang, Y., \& Frey, R. (2008). An automatic cloud mask algorithm based on time series of MODIS measurements. Journal of Geophysical Research, 113, D16207. http://dx.doi.org/10.1029/2007JD009641.

Lyapustin, A. Wang Y, Laszlo, In Kahn, R, Korkin, S, Remer, L, Levy, R, \& Reid, J. S. (2011b). Multi-angle implementation of atmospheric correction (MAIAC): Part 2. Aerosol algorithm. Journal of Geophysical Research, 116, D03211. http://dx.doi.org/ 10.1029/2010JD014986.

Lyapustin, A., Wang, Y., Laszlo, I., \& Korkin, S. (2012). Improved cloud screening in MAIAC aerosol retrievals using spectral and spatial analysis. Atmospheric Measurement Techniques Discussions, 5, 1575-1595. http://dx.doi.org/10.5194/amtd-5-1575-2012.

Malhi, Y., Roberts, J. T., Betts, R. A., Killeen, T. J., Li, W. H., \& Nobre, C. A. (2008). Climate change, deforestation, and the fate of the Amazon. Science, 319, 169-172.
Medlyn, B. E. (2011). Comment on "Drought-Induced Reduction in Global Terrestrial Net Primary Production from 2000 Through 2009". Science, 333. http://dx.doi.org/ 10.1126/science.1199048.

Mollicone, D., Freibauer, A., Schulze, E. D., Braatz, S., Grassi, G., \& Federici, S. (2007). Elements for the expected mechanisms on 'reduced emissions from deforestation and degradation, REDD' under UNFCCC. Environmental Research Letters, 2, 045024.

Myneni, R., \& Asrar, G. (1994). Atmospheric effects and spectral vegetation indices. Remote Sensing of Environment, 47, 390-402.

Rossow, W. B., \& Garder, L. C. (1993). Cloud detection using satellite measurements of infrared and visible radiances for ISCCP. Journal of Climate, 6, 2341-2369.

Roujean, J. L., Leroy, M., \& Deschamps, P. Y. (1992). A Bidirectional Reflectance Model of the Earths Surface for the Correction of Remote-Sensing Data. Journal of Geophysical Research-Atmospheres, 97(D18), 20455-20468.

Saleska, S. R., Didan, K., Huete, A. R., \& da Rocha, H. R. (2007). Amazon forests green-up during 2005 drought. Science, 318, 612-612.

Samanta, A Costa, M. H Nunes, E. L., Vieira, S. A. Xu, L \& Myneni, R. B. (2011). Comment on "Drought-induced reduction in global terrestrial net primary production from 2000 through 2009". Science, 333. http://dx.doi.org/10.1126/science.1199048.

Samanta, A., Ganguly, S., Hashimoto, H., Devadiga, S., Vermote, E., Knyazikhin, Y. Nemani, R. R., \& Myneni, R. B. (2010). Amazon forests did not green-up during the 2005 drought. Geophysical Research Letters, 37, L05401.

Samanta, A., Knyazikhin, Y., Xu, L., Dickinson, R. E., Fu, R., Costa, M. H., Saatchi, S. S., Nemani, R. R., \& Myneni, R. B. (2012). Seasonal changes in leaf area of Amazon forests from leaf flushing and abscission. Journal of Geophysical Research-Biogeosciences, 117, G01015.

Vermote, E. F., \& Kotchenova, S. (2008). Atmospheric correction for the monitoring of land surfaces. Journal of Geophysical Research-Atmospheres, 113, D23S90.

Vermote, E. F., Kotchenova, S. Y., \& Ray, J. P. (2008). MODIS surface reflectance user's guide v 1.2. http://modis-sr.ltdri.org

Wang, Y., Lyapustin, A., Privette, J., Cook, R., SanthanaVannan, S. K., Vermote, E., \& Schaaf, C. (2010). Assessment of biases in MODIS surface reflectance due to Lambertian approximation. Remote Sensing of Environment, 114, 2791-2801. http://dx.doi.org/ 10.1016/j.rse.2010.06.013.

Werth, D., \& Avissar, R. (2002). The local and global effects of Amazon deforestation. Journal of Geophysical Research-Atmospheres, 107, 8087.

Xiao, X. M., Braswell, B., Zhang, Q. Y., Boles, S., Frolking, S., \& Moore, B. (2003). Sensitivity of vegetation indices to atmospheric aerosols: Continental-scale observations in Northern Asia. Remote Sensing of Environment, 84, 385-392.

Xu, L., Samanta, A., Costa, M. H., Ganguly, S., Nemani, R. R., \& Myneni, R. B. (2011). Widespread decline in greenness of Amazônian vegetation due to the 2010 drought. Geophysical Research Letters, 38, L07402.

Yang, Y. K., \& Di Girolamo, L. (2008). Impacts of 3-D radiative effects on satellite cloud detection and their consequences on cloud fraction and aerosol optical depth retrievals. Journal of Geophysical Research-Atmospheres, 113, D04213.

Zelazowski, P., Sayer, A. M., Thomas, G. E., \& Grainger, R. G. (2011). Reconciling satellitederived atmospheric properties with fine-resolution land imagery: Insights for atmospheric correction. Journal of Geophysical Research-Atmospheres, 116 D18308.

Zhao, M. S., \& Running, S. W. (2010). Drought-induced reduction in global terrestrial net primary production from 2000 through 2009. Science, 329, 940-943. 